\title{
SWB MIMO Antenna with Dual Band Rejection Characteristics and Polarization Diversity for UWB Applications
}

Faezeh Bahmanzadeh

Shiraz University

Farzad Mohajeri ( $\square$ mohajeri@shirazu.ac.ir)

Shiraz University https://orcid.org/0000-0002-0444-7614

\section{Research Article}

Keywords: Band-notched characteristics, Elliptic single complementary split-ring resonators (ESCSRRs), Polarization diversity, Super wide band (SWB) antennas, UWB applications.

Posted Date: June 3rd, 2021

DOI: https://doi.org/10.21203/rs.3.rs-555061/v1

License: (c) (i) This work is licensed under a Creative Commons Attribution 4.0 International License.

Read Full License 


\title{
SWB MIMO Antenna with Dual Band Rejection Characteristics
}

\section{and Polarization Diversity for UWB Applications}

\author{
Faezeh Bahmanzadeh ${ }^{1}$, Farzad Mohajeri $^{2, *}$ \\ 1 M.Sc., Department of Communications and Electronics, School of Electrical and Computer Engineering, Shiraz \\ University, Shiraz, Iran. \\ ${ }^{2}$ Associate Professor, Department of Communications and Electronics, School of Electrical and Computer Engineering, \\ Shiraz University, Shiraz, Iran. \\ *Corresponding author. \\ E-mail: f.bahmanzadeh@shirazu.ac.ir (F.Bahmanzadeh), mohajeri@shirazu.ac.ir (F.Mohajeri).
}

\begin{abstract}
In this paper a super wide band 2-element MIMO antenna with dual band-notched characteristics and high isolation is presented for use in broadband polarization diversity communication systems. Total dimensions of the fabricated antenna is $34 \times$ $60 \mathrm{~mm}^{2}$ and achieves a super wide impedance matching of more than $15 \mathrm{GHz}$ from 2.3 to $18 \mathrm{GHz}$ due to the simulated and measured results which covers $\mathrm{L}, \mathrm{S}, \mathrm{C}, \mathrm{X}, \mathrm{Ku}$ bands and some parts of $\mathrm{K}$ band with two notched frequency bands around $3.1-3.7 \mathrm{GHz}$ for WiMAX and 5.1 - 5.8 GHz for WLAN which realized by etching two half-wavelength elliptic single complementary split-ring resonators (ESCSRRs) of different dimensions on the radiating patches. This antenna comprises two identical elements which placed orthogonally to each other and fed by two $50 \Omega$ coplanar waveguide (CPW) lines, therefore an isolation of more than $20 \mathrm{~dB}$ is obtained autonomously without utilizing any other special technique. Diversity performance in terms of envelop correlation coefficient $(\mathrm{ECC}<0.0035)$, multiplexing efficiency $\left(\eta_{\text {mux }}>-1 \mathrm{~dB}\right)$ and diversity gain $(\mathrm{DG}>9.99 \mathrm{~dB})$ are also calculated, showing satisfactory MIMO characteristics.
\end{abstract}

Keywords: Band-notched characteristics, Elliptic single complementary split-ring resonators (ESCSRRs), Polarization diversity, Super wide band (SWB) antennas, UWB applications.

\section{Introduction}

Microstrip antennas are considered as the most common types of antennas during the past few years due to their obvious advantages of light weight, low cost, low profile, planar configuration, superior portability, easy for fabrication, and easy integration with microwave monolithic integrated circuits (MMICs) [1] and ever since the Federal Communication Commission (FCC) assigned ultra-wide band (UWB) frequency range from 3.1 to $10.6 \mathrm{GHz}$, UWB technology have gained so much attention [2]. Meanwhile SWB antennas become prevalent which cover both long-range and short-range communication that includes the UWB range and is an integral part in advanced wireless communication. Along with all the above advantages, multipath fading, reliability 
limitations and interfering some existing narrowband communication systems such as WiMAX, WLAN and X-band, are some important problems that should be solved well for UWB and SWB systems. In this regard numerous researches have been allocated and it has been confirmed that UWB-MIMO wireless communication combining UWB technology with multiple input multiple output (MIMO) technology can effectively increase the channel capacity and reliability of the system, reduce the channel error rate, increase the working bandwidth, and overcome multipath fading of UWB communication systems without requiring any additional bandwidth consumption therefore UWB-MIMO antenna design in the field of wireless communications has received more and more attention [3-6]. The UWB-MIMO systems require compact antennas with good isolation between the ports. As regards with that, several techniques have been studied and utilized to improve the isolation between the elements of MIMO antennas while maintaining their small electrical lengths. For example to reduce the mutual coupling between the ports of the proposed 2-element MIMO antennas in [7] and [8] a $\varepsilon$-negative metasurface superstrate and a fractal isolator which is an electromagnetic band gap (EBG) structure based on metamaterial is introduced between the elements respectively and isolation of more than $25 \mathrm{~dB}$ and $31 \mathrm{~dB}$ is obtained in each case. Also in [9] and [10] by using the neutralization line technique, the mutual coupling between the radiating patches is reduced to less than $-22 \mathrm{~dB}$ in each case. In [11-13] elements of the MIMO antennas are placed orthogonal to each other and the polarization or pattern diversity cause high isolation of more than $20 \mathrm{~dB}$ for each antenna. Also to suppress the interferences of the mentioned narrowband systems, different methods such as etching inverted L-shape [14], U-shape [15] and T-shape [16] slots of different dimensions on the ground plane, on the feed line and on the radiating patch have been proposed, respectively. Embedding different types of split-ring resonators on the radiating patch [17] and [18], placing various strips near the feed-line [19], or near the ground plane [20], utilizing parasitic elements such as bended dual L-shaped branches on the patch [21] and using substrate integrated waveguide (SIW) based metallic via integration of hexagonal and semi-hexagonal parasitic slot [22], have been utilized to obtain UWB antennas with single or several band-notched characteristics. In [23] three open ended slots are introduced into the radiating patch to filter WiMAX, WLAN and X-band interferences and in [24] a monopole antenna with six band-notched characteristics is presented based on SRRs and U-shaped parasitic strips and notched bands around 2.96-3.33 GHz, 3.73- 3.88 GHz 4.43-4.53 GHz, 5.37-5.57 GHz, 7.02-7.30 GHz and 7.56-8.06 GHz have been obtained. Also in [25] a dual band-notched MIMO antenna is proposed with a total size of $25 \times 39 \mathrm{~mm}^{2}$ and impedance bandwidth from 2.6 to 12.5 $\mathrm{GHz}$. In this work, to reduce mutual coupling to less than $-20 \mathrm{~dB}$ the elements placed perpendicular to each other and to filter the interferences of WLAN and X-band, two L-shaped slots are etched on each radiating patches.

In this paper a compact single-layer dual band-notched SWB MIMO antenna with high isolation and polarization diversity is proposed. The total size of this design is about $34 \times 60 \times 1.6 \mathrm{~mm}^{3}$ which is small compare to some previous researches [26] and [27] and consist of two identical monopole antennas. Each monopole has a simple circular patch which fed by a $50 \Omega$ CPW line and placed perpendicular to each other with shared ground at the small spatial distance of only $2 \mathrm{~mm}$. Towards realizing rejection bands, two ESCSRRs of different dimensions are embedded on each radiating patched for WiMAX and WLAN bands which 
operate between 3.3 to $3.7 \mathrm{GHz}$ and 5.1 to $5.825 \mathrm{GHz}$ for each bands respectively. Also impedance bandwidth of the antenna broadened by introducing two large elliptic slots on the shared ground plane and the bandwidth of more than $153 \%$ is achieved from 2.3 to $18 \mathrm{GHz}$. Even though the distance between the elements is too small, the mutual coupling of less than $-20 \mathrm{~dB}$ is accomplished autonomously thanks to polarization diversity. It is noteworthy to mention that each element separately, is a single input single output (SISO) SWB antenna with dual band rejection characteristics having the size of $31 \times 31 \times 1.6 \mathrm{~mm}^{3}$. The designed MIMO antenna provides omnidirectional radiation pattern at xoz plane and near $6 \mathrm{dBi}$ of peak gain for each port. Also the value of ECC, multiplexing efficiency and diversity gain are better than 0.035 and $-1 \mathrm{~dB}$ and $9.99 \mathrm{~dB}$ respectively. The salient feature in this design is to provide SWB impedance matching for each port with two rejection bands for WLAN and WiMAX, along with the simple structure and small dimensions.

\section{Design methodology of the proposed antenna}

\subsection{Single element SWB dual band-notched antenna}

Fig. 1(a) shows the configuration of the single input single output super wide band antenna with dual band-notched characteristics. The SISO antenna having the size of is $31 \times 31 \times 1.6 \mathrm{~mm}^{3}$ where consists of a simple circular patch which fed by a $50 \Omega \mathrm{CPW}$ line with $0.25 \mathrm{~mm}$ gap between the strips and ground plane to reach reasonable impedance matching, and defected ground plane which placed on the top side of the FR-4 substrate having the size of $\mathrm{W}_{1} \times \mathrm{L}$, relative electric permittivity of 4.4 and loss tangent of 0.02. A large elliptic slot having the major radius of $D_{\max }=30 \mathrm{~mm}$ and minor radius of $\mathrm{D}_{\min }=23 \mathrm{~mm}$ is etched into the ground plane to enhance the bandwidth of the antenna to more than $15 \mathrm{GHz}$ from 2.3 to $18 \mathrm{GHz}$ covers $\mathrm{L}, \mathrm{S}, \mathrm{C}, \mathrm{X}, \mathrm{Ku}$ bands and some parts of $\mathrm{K}$ band.

Two half wavelength ESCSRRs of different dimensions are introduced into the radiating patch to filter the interferences of WiMAX (3.3-3.7 GHz) and WLAN (5.1-5.825 GHz) bands. The proper length of each ESCSRRs can be obtained from the following equation and the location of them on the radiating patch have been optimized [18].

$$
L_{s n}=K_{e} \pi\left(0.5 D_{n+1}-w\right)-g \approx \frac{\lambda_{g}}{2}=\frac{c}{2 f_{\text {Notch }} \sqrt{\varepsilon_{\mathrm{eff}}}}
$$

Where

$$
K_{e}=3\left(1+k_{n}\right)-\sqrt{\left(3+k_{n}\right)\left(1+3 k_{n}\right)}
$$

Where $L_{s n}$ is the total length of the elliptic slots which should be approximately equal to half of the guided wavelength $\lambda_{g}$ at the desired notch frequencies and $K_{e}$ used for the calculation of the circumference of each ellipse with ellipticity $k_{1}=D_{1} / D_{2}$. For $\mathrm{n}=1$ and $\mathrm{n}=2$ WiMAX and WLAN band rejection were obtained respectively. The thickness of each ESCSRRs is $\omega=0.3 \mathrm{~mm}, f_{\text {Notch }}$ 
is the central frequency of the notched bands and $c$ is the speed of light in free space. Also $\varepsilon_{\text {eff }}$ can obtain from the following equation [18].

$$
\varepsilon_{\text {eff }}=\frac{\varepsilon_{r}+1}{2}+\frac{\varepsilon_{r}-1}{2}\left(1+\frac{12 h}{w_{f}}\right)^{-1 / 2}
$$

Where $\varepsilon_{r}$ is the relative permittivity of substrate that is about 4.4 for FR-4, $h$ and $w_{f}$ are the thickness of the substrate and width of the microstrip feed line which is about $1.6 \mathrm{~mm}$ and $2.8 \mathrm{~mm}$ in this case, respectively. Fig. 1(b) shows the location of the ESCSRRs on the circular patch.

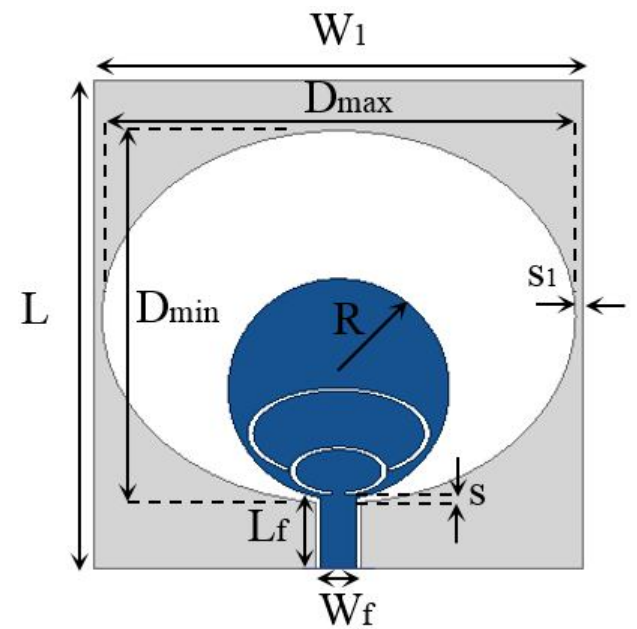

(a)

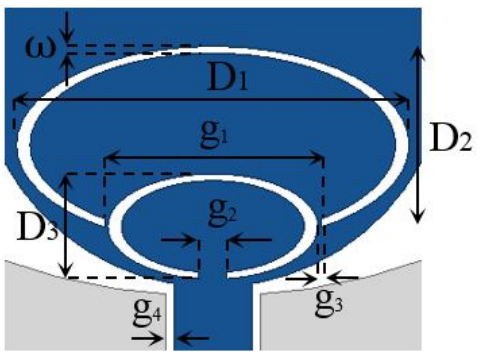

(b)

Fig. 1. The SISO SWB dual band-notched antenna. (a) Antenna configuration, (b) ESCSRRs.

The proposed SWB antenna is obtained after various modifications in design and presented in Fig. 2(a)-(d). Initially, Antenna 1 which comprises a circular patch having the radius of $\mathrm{R}=7 \mathrm{~mm}$ and a defected ground plane designed as shown in Fig. 2(a) which covers wide impedance bandwidth of 2.3 to $18 \mathrm{GHz}(\mathrm{VSWR}<2)$ without incorporating any notch as illustrated in Fig. 2(e). First ESCSRR having a total length of $\mathrm{L}_{S 1}=15.5 \mathrm{~mm}$ which obtained from equation 1 , is etched on the radiating patch (Antenna 2$)$ as shown in Fig. 2(b) aiming to reduce the interference of WiMAX equipment and a stop band around 2.9 to 3.8 GHz is appeared in SWB frequency range with VSWR $=9$ as shown in Fig. 2(e). Second ESCSRR having a total length of $\mathrm{L}_{\mathrm{S} 2}=9.6 \mathrm{~mm}$ is similarly introduced on the patch of Antenna 3 as shown in Fig. 2(c) aiming to reduce the interference of WLAN systems and single band notched characteristics achieved around 5.1 to $6.1 \mathrm{GHz}$ as shown in Fig. 2 (e) with VSWR =6.9. Fig. 2(d) shows the last step of the design procedure (Antenna 4) and includes both ESCSRRs on the patch which caused the notched bands around 2.9 to $3.9 \mathrm{GHz}$ and 5.1 to $6 \mathrm{GHz}$ at the super wide impedance bandwidth from 2.3 to $18 \mathrm{GHz}$ which is noticeable due to the compact size of the design. Fig. 2(e) depicts the comparison plot of VSWR at each step and final optimum dimensions of the SISO designed antenna are given in Table 1. 


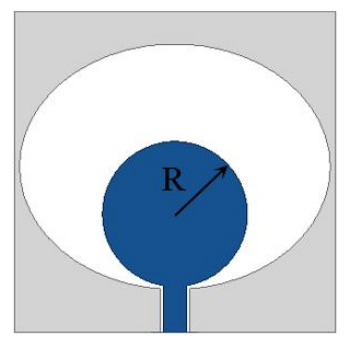

(a)

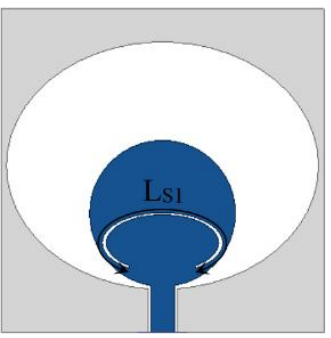

(b)

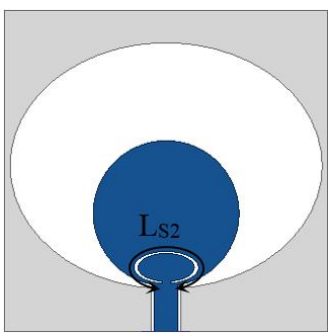

(c)

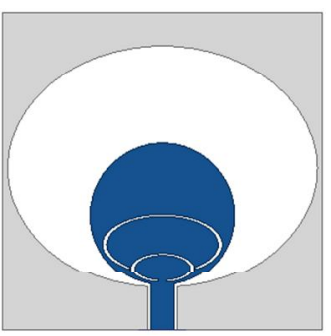

(d)

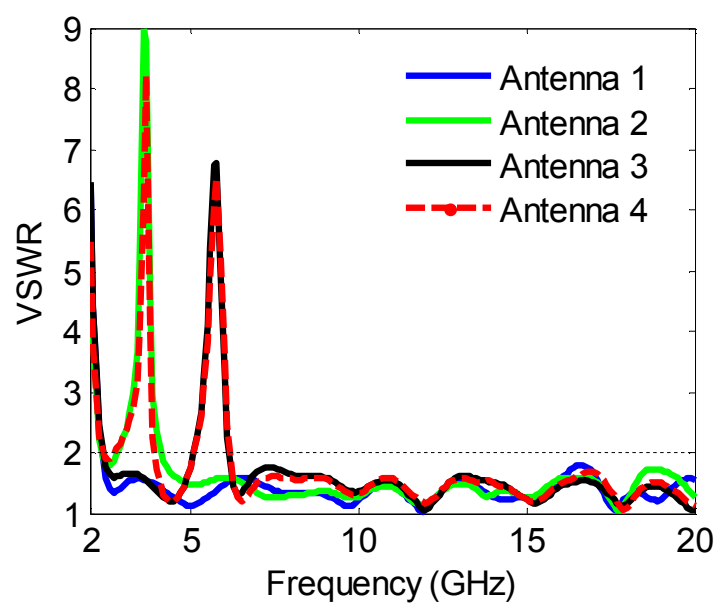

(e)

Fig. 2. The design stages of the SISO SWB dual band-notched antenna, (a) Antenna 1, (b) Antenna 2, (c) Antenna 3, (d) Antenna 4 and (e) Simulated VSWR curves for each step.

Table 1. Final optimum dimensions of the SISO SWB dual band-notched antenna.

\begin{tabular}{|cccc|}
\hline Parameters & $\begin{array}{c}\text { Dimension } \\
(\mathrm{mm})\end{array}$ & Parameters & $\begin{array}{c}\text { Dimension } \\
(\mathrm{mm})\end{array}$ \\
\hline W1 & 31 & $\mathrm{Wf}$ & 2.3 \\
L & 31 & $\mathrm{Lf}$ & 4.5 \\
D1 & 11.4 & $\mathrm{~s}$ & 0.6 \\
D2 & 5.4 & $\mathrm{~s} 1$ & 0.5 \\
D3 & 2.8 & $\mathrm{~g} 1$ & 5.5 \\
R & 7 & $\mathrm{~g} 2$ & 0.84 \\
Dmax & 30 & $\mathrm{~g} 3$ & 0.1 \\
Dmin & 23 & $\mathrm{~g} 4$ & 0.25 \\
\hline
\end{tabular}

\subsection{Proposed MIMO SWB dual band-notched antenna}

Designed single element antenna that presented in previous section, is converted to a 2-port MIMO antenna by placing the SISO elements perpendicular to each other with shared ground at the spatial distance of only $2 \mathrm{~mm}$ as shown in Fig. 3(a), therefore, a super wide impedance matching and low mutual coupling can be achieved through the whole operating bandwidth. Fig. 3(b) shows 
the fabricated prototype of the designed MIMO antenna. The total dimensions of this antenna is about $34 \times 60 \times 1.6 \mathrm{~mm}^{3}$ and fabricated on FR-4 substrate. The given parameters in Table 1 remain unchanged for designing the SWB MIMO antenna and additional parameters are given as follows: $\mathrm{W}=34 \mathrm{~mm}, \mathrm{~L}=60 \mathrm{~mm}, \mathrm{~s} 3=0.6 \mathrm{~mm}, \mathrm{~s} 4=0.5 \mathrm{~mm}$.

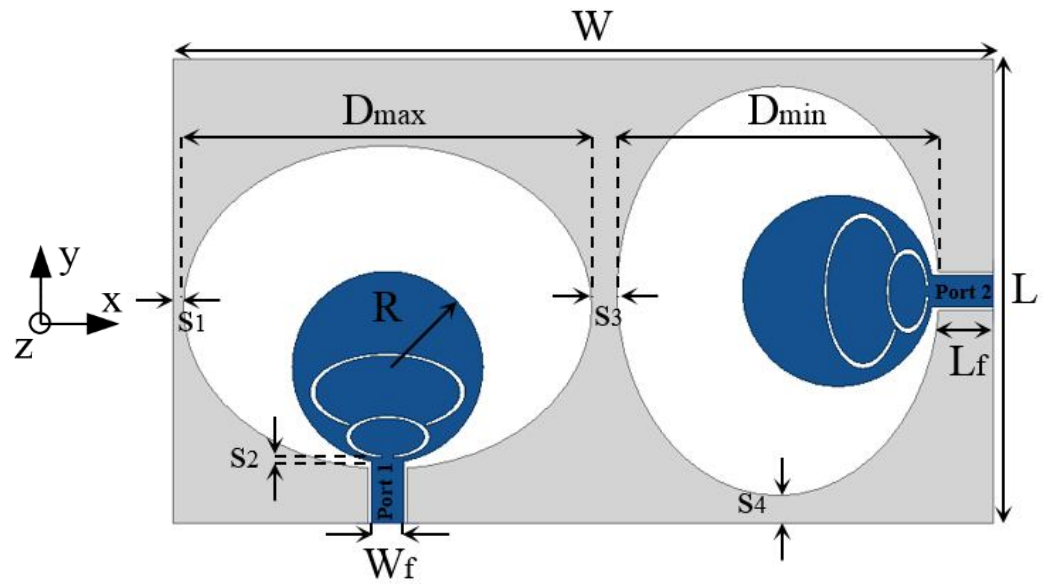

(a)

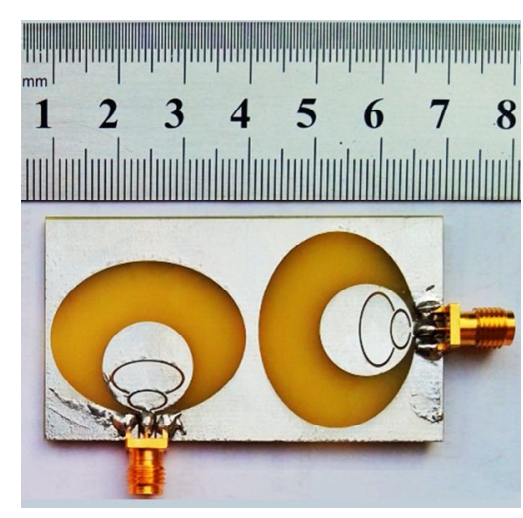

(b)

Fig. 3. The SWB dual band-notched MIMO antenna, (a) Antenna configuration, (b) fabricated prototype.

Simulated S-Parameters $\left(S_{11}, S_{12}, S_{21}\right.$ and $\left.S_{22}\right)$ of the designed SWB MIMO antenna are shown in Fig. 4. As shown in this figure, the antenna can provides super wide impedance bandwidth from 2.3 to more than $18 \mathrm{GHz}$ and rejects the WiMAX and WLAN bands from 2.9 to $3.8 \mathrm{GHz}$ and 5.1 to $6.1 \mathrm{GHz}$ at each port. Also mutual coupling is reduced by placing the two similar elements orthogonally to each other and an isolation of more than $20 \mathrm{~dB}$ is achieved even though the ground planes are closely connected. Orthogonally of radiating elements is enough to meet high isolation without the need of any other special decoupling technique.

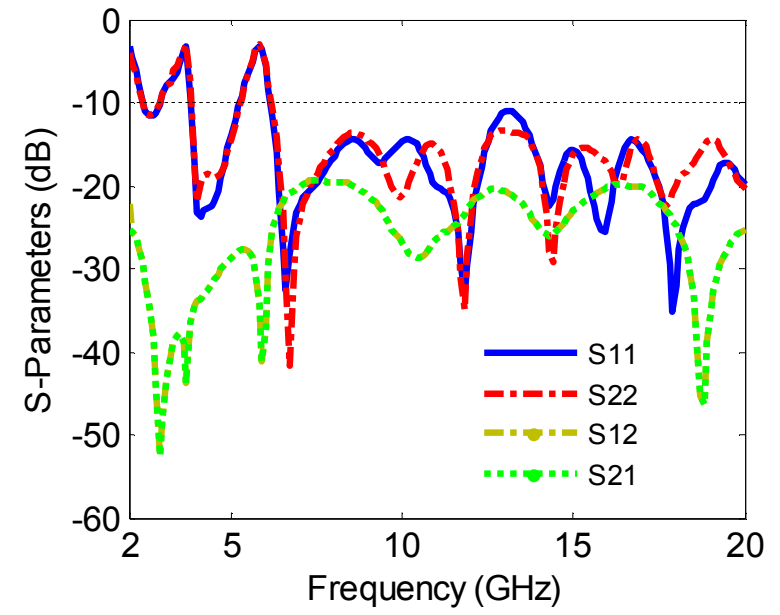

Fig. 4. Simulated S-parameters $\left(S_{11}, S_{12}, S_{21}\right.$ and $\left.S_{22}\right)$ of the designed SWB dual band-notched MIMO antenna. 


\subsection{Current distribution and notch performance}

In this section notched mechanism of the antenna is analyzed in detail from the surface current distributions and parametric study. Fig. 5 illustrates VSWR plot of the SWB MIMO antenna for different values of $L_{s 1}$ and $L_{s 2}$ (total dimension of each resonator). First $L_{S 1}$ is fixed at $10.5 \mathrm{~mm}$ with the central frequency of $3.6 \mathrm{GHz}$ and $L_{S 2}$ varied from 6.9 to $8.1 \mathrm{~mm}$ and by increasing the length of smaller ESCSRR, the center frequency of the second notched band will shifted in the amount of $1 \mathrm{GHz}$ from 6.3 to 5.3 GHz as depicted in Fig. 5(a) while other rejected band are approximately unchanged. Similarly when $L_{S 2}$ is fixed at $7.6 \mathrm{~mm}$ with the central frequency of $5.8 \mathrm{GHz}$ and $L_{S 1}$ varied from 9.9 to $11.1 \mathrm{~mm}$, the center frequency of the first notched band will shifted in the amount of $1 \mathrm{GHz}$ from 4.2 to $3.2 \mathrm{GHz}$ as depicted in Fig. 5(b). It is evident from the parametric analysis of $L_{s 1}$ and $L_{s 2}$ that the dimensions of each resonator controlled the resonance notch frequency and by changing total size of each ESCSRRs, the resonance notch frequency could be shifted easily meanwhile the different notch bands can change independently without affecting each other's function. For further elaboration on the effects of ESCSRRs, simulated surface current distribution of the designed MIMO antenna is studied and shown in Fig. 6 at notched central frequencies when port 1 is exited ant port 2 is terminated by a $50 \Omega$ matched load. Fig. 6(a), depicts current distribution at 3.6 GHz. In this figure the concentration of surface currents are around the larger ESCSRR, which filter WiMAX frequency band, and Fig. 6(b), shows surface currents at 5.7 GHz. similarly surface currents are more dominant around the smaller ESCSRR which filter WLAN frequency band so current flow on the radiating elements is blocked and reduced the radiation energy in the desired band. As it is clear in this figure, current distribution perturbed by the presence of ESCSRRs and also it is evident from this figure that the mutual coupling among the elements is small, hence the proposed MIMO antenna has a good isolation.

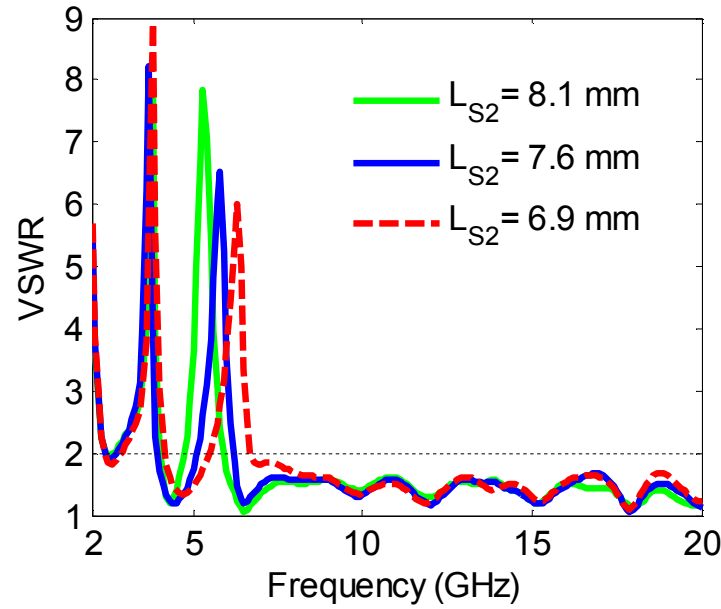

(a)

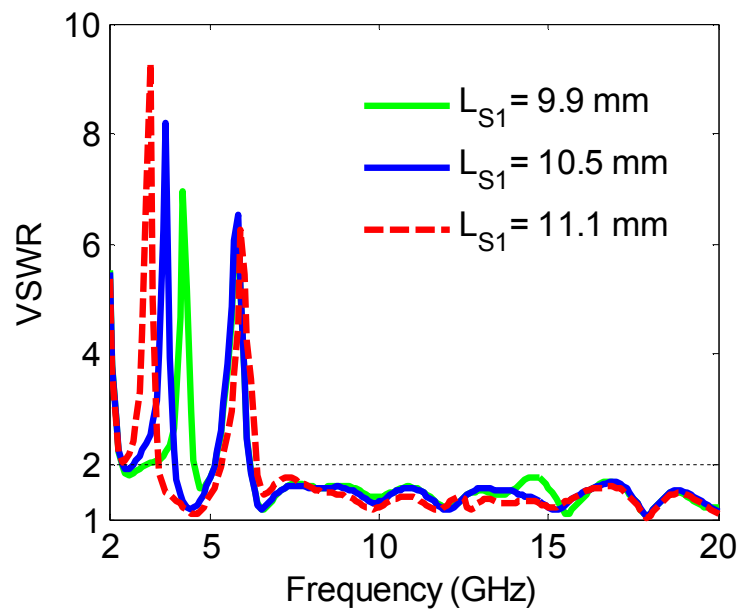

(b)

Fig. 5. Parametric study of the total length variation of ESCSRRs, (a) $L_{S 2}$, (b) $L_{S 1}$. 


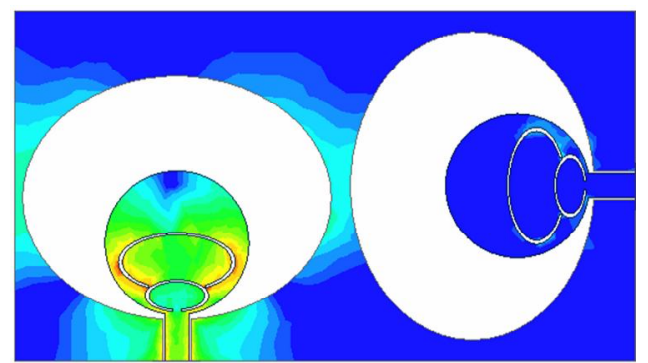

(a)

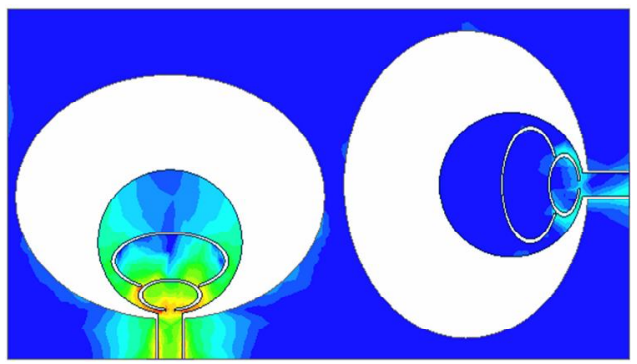

(b)
Jsurf [A_per_m]

1. $0871 \mathrm{e}+003$

7. $0592 \mathrm{e}+002$

4. $5841 \mathrm{e}+002$

2. $9768 e+002$

1. $9331 \mathrm{e}+002$

1. $2553 e+002$

8. $1518 \mathrm{e}+001$

5. $2936 \mathrm{e}+001$

3. $4376 \mathrm{e}+001$

2. $2323 e+001$

1. $4496 \mathrm{e}+001$

9. $4135 e+000$

6. $1130 e+000$

3. $9697 e+000$

2. $5778 e+000$

1. $6740 \mathrm{e}+000$

1. $0871 \mathrm{e}+000$

Fig. 6. Surface current distribution of the band-notched antenna (a) $3.6 \mathrm{GHz}$, (b) $5.8 \mathrm{GHz}$.

\section{Fabrication and measured results}

The fabricated prototype of the antenna with the optimized dimensions mentioned in Section 2, was measured to validate the accuracy of simulated results. Fig. 7 illustrates the simulated and measured VSWR at each port and amplitude of $S_{12}$ parameter. The proposed antenna offers good impedance bandwidth (VSWR < 2) from 2.3 to more than $18 \mathrm{GHz}$ (IBW 153\%) with band notches at 2.9 to $3.8 \mathrm{GHz}$ and 5.1 to $6.1 \mathrm{GHz}$ for each port due to both simulated and measured results as demonstrated in Fig. 7(a). Also the amplitude of simulated and measured mutual coupling $\left(S_{12}\right)$ values are less than $-20 \mathrm{~dB}$ in the entire operating band as shown in Fig. 7 (b). Good agreement is identified between the simulated and measured results from this figure.

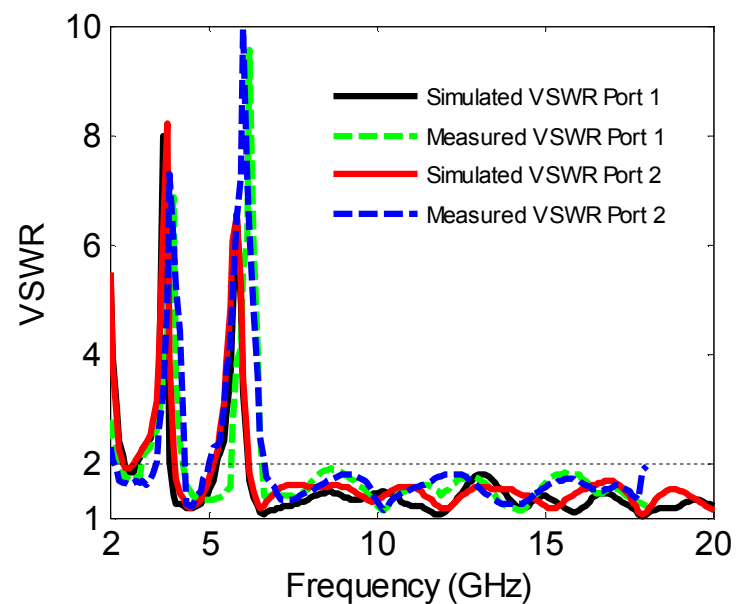

(a)

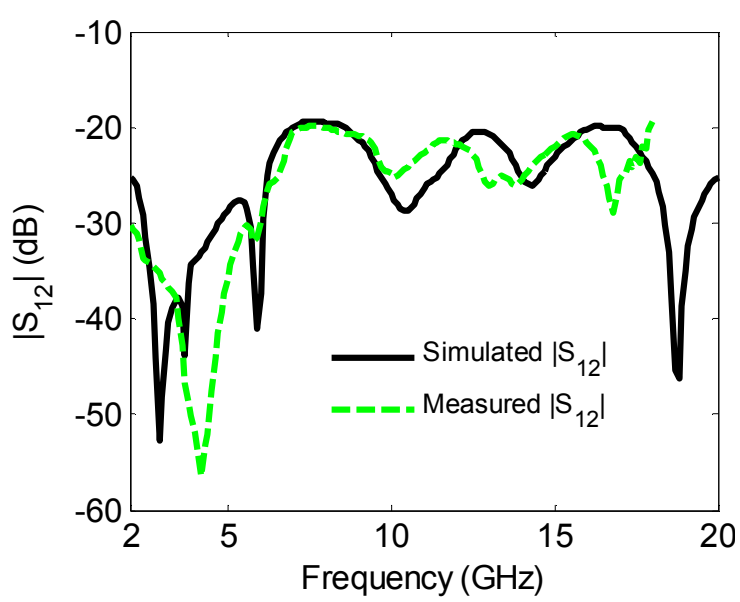

(b)

Fig. 7. Simulated and measured (a) VSWR parameters for each port, (b) amplitude of mutual coupling $\left(\mathrm{S}_{12}\right)$. 
Simulated 2-D radiation patterns of the proposed MIMO antenna in xoz and yoz planes, at 3, 10 and $17 \mathrm{GHz}$ when port 1 is exited and port 2 is matched by a $50 \Omega$ load and vice-versa are shown in Fig. 8 . As shown in these figures, the radiation patterns at port 1 and port 2 are nearly similar with approximately a $90^{\circ}$ rotation, showing a good orthogonal polarization operation of the antenna. The proposed MIMO antenna radiates almost omnidirectional patterns in xoz and yoz planes $\left(\varphi=0^{\circ}\right.$ and $\varphi=90^{\circ}$ respectively) when port 1 is exited and port 2 is matched by a $50 \Omega$ load and vice-versa also provides bidirectional radiation patterns in yoz and xoz planes when port 2 is exited and port 1 is matched by a $50 \Omega$ load and vice versa and also the cross polarization component values are below $-18 \mathrm{~dB}$ at each frequency and in both plane.
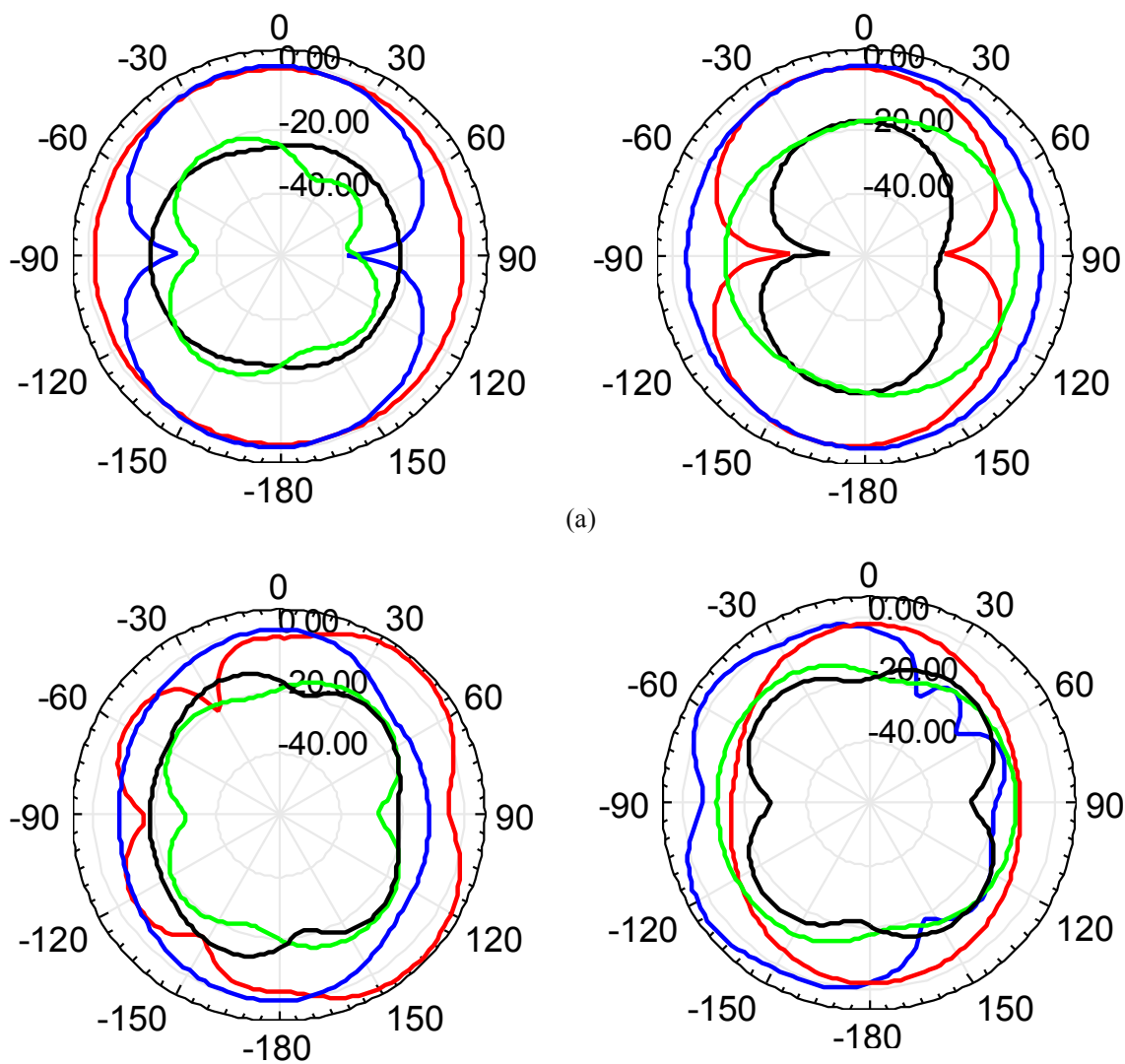

(b)
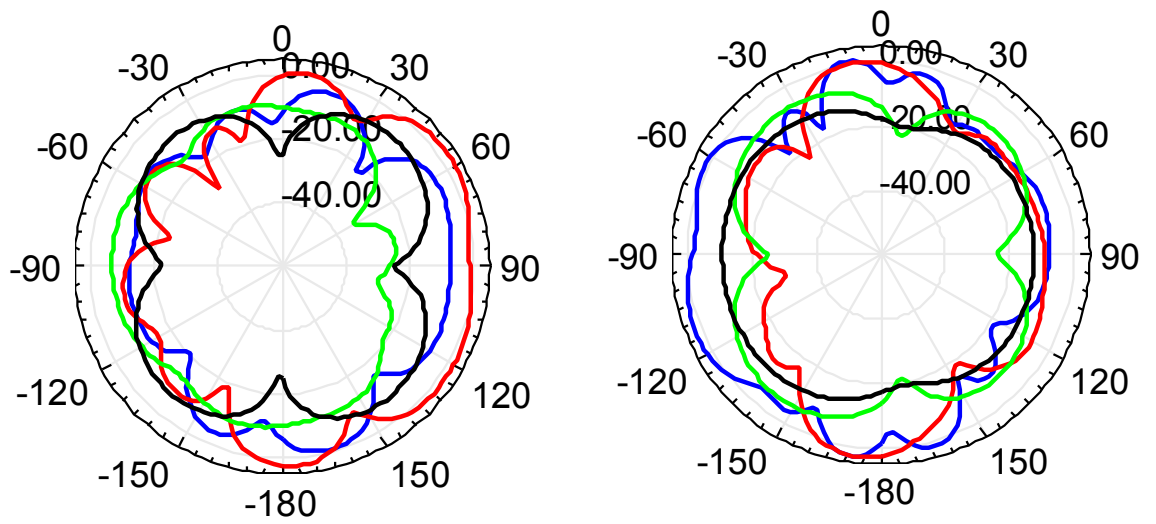

(c) 


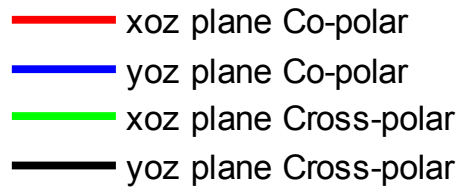

Fig. 8. Simulated radiation patterns in $\operatorname{xoz}\left(\varphi=0^{\circ}\right)$ and yoz $\left(\varphi=90^{\circ}\right)$ planes at (a) $3 \mathrm{GHz}$, (b) $10 \mathrm{GHz}$, (c) $17 \mathrm{GHz}$, when port 1 is excited

and port 2 terminated by a matched load (right), port 2 is excited and port 1 terminated by a matched load (left).

MIMO diversity performance characteristics such as Envelope Correlation Coefficient (ECC), diversity gain (DG) and multiplexing efficiency $\left(\eta_{\text {mux }}\right)$ of the suggested MIMO antenna have been studied and can obtain from the following equations. ECC utilized to evaluate correlation between radiation patterns. Uncorrelated radiation patterns is one of the fundamental requirements for elements of a MIMO antenna to be effectively utilized in pattern diversity.

ECC can be evaluated using S-parameters by equation (4) [28]:

$$
E C C=\frac{\left|S_{11}^{*} S_{21}+S_{21}^{*} S_{22}\right|^{2}}{\left(1-\left(\left|S_{11}\right|^{2}+\left|S_{21}\right|^{2}\right)\right)\left(1-\left(\left|S_{22}\right|^{2}+\left|S_{21}\right|^{2}\right)\right)}
$$

Where $S_{11}$ and $S_{22}$ are the reflection coefficients of the two ports and $S_{12}$ and $S_{21}$ are the coupling between two ports. Another important parameter for MIMO diversity performance is diversity gain (DG) which is the figure of merit and used to quantitatively evaluate the performance level of various diversity techniques and defined with equation (5) [28]. Also multiplexing efficiency $\left(\eta_{\text {mux }}\right)$ is an advantageous metric to optimize channel capacity which define the imbalance between antenna efficiency and correlation and calculated by relation (6) [29].

$$
\begin{aligned}
& D G=\sqrt{1-E C C^{2}} \\
& \eta_{\text {mux }}=\sqrt{\eta_{1} \eta_{2}\left(1-|r|^{2}\right)}
\end{aligned}
$$

Where $\eta_{1}$ and $\eta_{2}$ are the total efficiencies of port 1 and port 2 respectively and $|r|^{2}$ is the square root of magnitude of the complex correlation between the two elements of MIMO antenna and it is almost equal to ECC.

Simulated and measured peak gain for port 1 and 2 and simulated multiplexing efficiency of the suggested MIMO antenna are depicted in Fig. 9. It can be observed from this figure that peak gain of the antenna is about $6.3 \mathrm{dBi}$ for each port and decreases sharply at the center of notched frequencies. Also multiplexing efficiency is less than $-1 \mathrm{~dB}$ excluding the two rejected bands and decrease to less than -5 and $-4 \mathrm{~dB}$ for WiMAX and WLAN rejection bands respectively as it is clear from this figure. ECC and DG also plotted in Fig. 10. For uncorrelated diversity antenna the ideal value of ECC should be zero but practical limit for that, is less than 0.5. The ECC of the proposed antenna is less than 0.004 through the entire frequency band including the notched bands which indicates such an excellent diversity performance and very low correlation between the radiators. Also DG which is another performance metric of MIMO antenna is better than $9.99 \mathrm{~dB}$ as shown in Fig. 10. 
The comparison between the proposed antenna and eight other designed MIMO antennas are given in Table. 2. Size, working band width, the number of notched bands, multiplexing efficiency, the number of elements, isolation and ECC are contrasted in this table for various antennas. It can be concluded that the proposed antenna has better radiation properties.

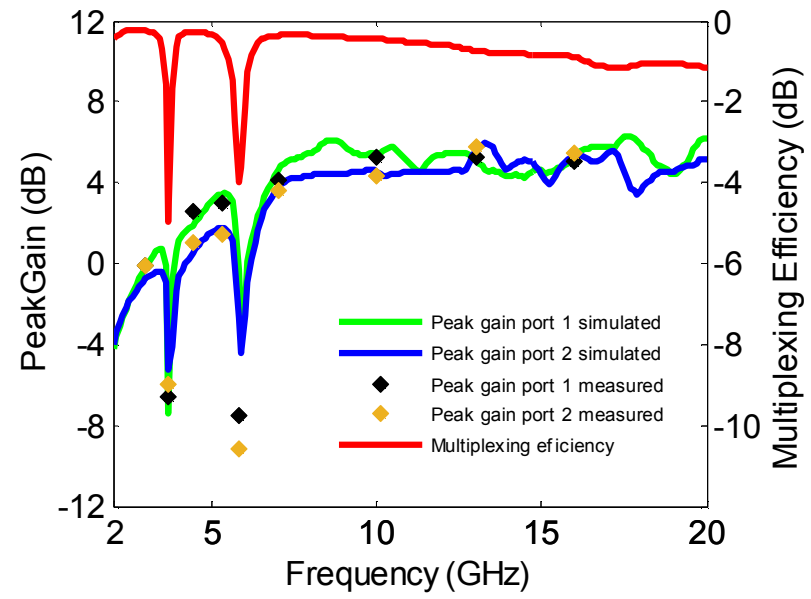

Fig. 9. Simulated peak gain and multiplexing efficiency of the designed SWB MIMO antenna.

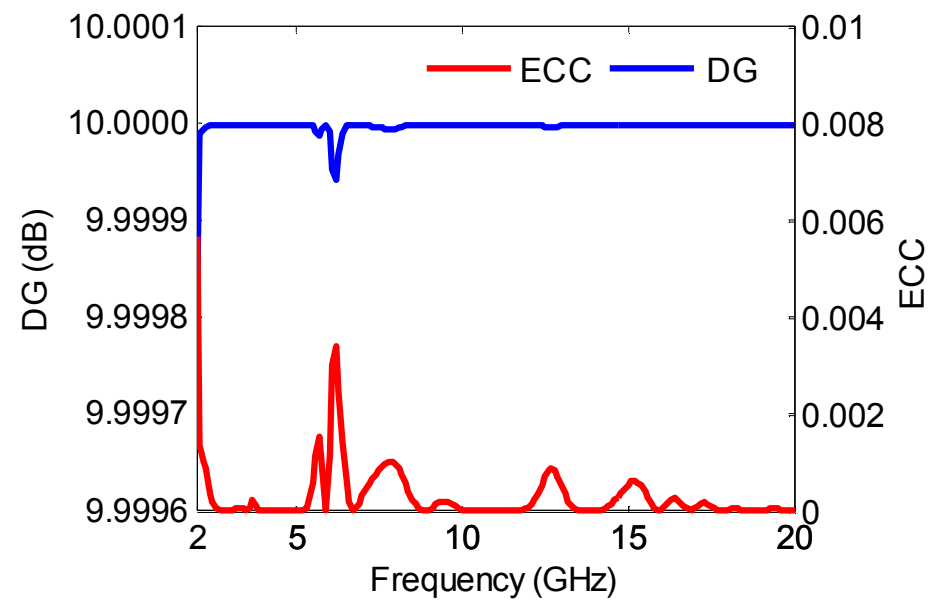

Fig. 10. Simulated DG and ECC of the designed SWB dual band-notched MIMO antenna.

Table 2. Comparison of proposed SWB band-notched MIMO antennas with recently reported designs.

\begin{tabular}{|c|c|c|c|c|c|c|c|c|c|}
\hline Ref. & $\begin{array}{c}\text { Size } \\
\left(\mathbf{m m}^{2}\right)\end{array}$ & $\begin{array}{c}\text { BW } \\
(\mathbf{G H z})\end{array}$ & $\begin{array}{c}\text { Isolation } \\
(\mathbf{d B})\end{array}$ & $\begin{array}{c}\text { No. of } \\
\text { notches }\end{array}$ & Ports & ECC & $\begin{array}{c}\text { DG } \\
\mathbf{( d B})\end{array}$ & $\begin{array}{c}\text { MUX Eff. } \\
\mathbf{( d B})\end{array}$ & $\begin{array}{c}\text { Applied } \\
\text { decoupling } \\
\text { technique }\end{array}$ \\
\hline$[4]$ & $40 \times 50$ & $2.5-11$ & $>15$ & - & 2 & $0.01>$ & NA & NA & $\begin{array}{c}\text { Utilizing a } \\
\text { carbon } \\
\text { black film }\end{array}$ \\
\hline$[9]$ & $34 \times 48$ & $3.5-10$ & $>23$ & - & 4 & $0.039>$ & $>9.8$ & NA & $\begin{array}{c}\text { Using the } \\
\text { neutralizati } \\
\text { on line }\end{array}$ \\
\hline$[17]$ & $26 \times 41$ & $3.1-11.5$ & $>15$ & 3 & 2 & $0.01>$ & $>9.5$ & NA & $\begin{array}{c}\text { Using } \\
\text { Minkowski } \\
\text { fractal DGS }\end{array}$ \\
\hline
\end{tabular}




\begin{tabular}{|c|c|c|c|c|c|c|c|c|c|}
\hline$[19]$ & $26 \times 26$ & $2.9-11.6$ & $>16$ & 2 & 2 & $0.02>$ & NA & NA & $\begin{array}{c}\text { Etching T- } \\
\text { shaped slot } \\
\text { in the } \\
\text { ground } \\
\text { plane }\end{array}$ \\
\hline$[22]$ & $54 \times 54$ & $3-40$ & $>20$ & 3 & 8 & $0.02>$ & $>9.9$ & $>-2$ & $\begin{array}{c}\text { a novel } \\
\text { hexagonal- } \\
\text { ring type } \\
\text { fencing }\end{array}$ \\
\hline$[25]$ & $25 \times 39$ & $2.8-11.2$ & $>15$ & 2 & 2 & $0.15>$ & $>8.5$ & $>-1$ & $\begin{array}{c}\text { Diversity } \\
\text { and U- } \\
\text { shape } \\
\text { branches }\end{array}$ \\
\hline$[26]$ & $40 \times 50$ & $2.7-12$ & $>20$ & 1 & 4 & $0.025>$ & NA & NA & $\begin{array}{c}\text { Polarization } \\
\text { diversity }\end{array}$ \\
\hline$[27]$ & $58 \times 58$ & $3-13.5$ & $>22$ & 2 & 4 & $0.008>$ & NA & $>-2$ & $\begin{array}{c}\text { Diversity } \\
\text { and slotted } \\
\text { edge } \\
\text { substrate }\end{array}$ \\
\hline $\begin{array}{c}\text { This } \\
\text { work }\end{array}$ & $34 \times 60$ & $2.3-18$ & $>20$ & 2 & 2 & $0.004>$ & $>9.99$ & $>-1$ & $\begin{array}{c}\text { Polarization } \\
\text { diversity }\end{array}$ \\
\hline
\end{tabular}

\section{Conclusion}

In this work a dual band-notched SWB MIMO antenna with high isolation is designed and fabricated for polarization diversity communication systems. The total size of the antenna is $31 \times 65 \times 1.6 \mathrm{~mm}^{3}$ covering more than $15 \mathrm{GHz}$ impedance bandwidth from 2.3 to $18 \mathrm{GHz}$ at each port except at the two notched bands from 2.9 to $3.9 \mathrm{GHz}$ for WiMAX (3.3-3.7GHz) and 5 to $6.1 \mathrm{GHz}$ for WLAN (5.1-5.825GHz) which appears in the existence of two ESCSRRs on the two radiating patches. Also an isolation of more than $20 \mathrm{~dB}$ is obtained in the entire bandwidth. The presented antenna provides an excellent polarization diversity performance and peak gain of about $6.3 \mathrm{dBi}$ at each port, ECC of less than 0.01, DG better than $9.99 \mathrm{~dB}$, multiplexing efficiency above $-1 \mathrm{~dB}$ and nearly omnidirectional radiating pattern. Comparison results in Table 2 show that the proposed antenna has better performance for UWB and SWB applications yet the structure is simple and easy to fabricate.

\section{References}

[1] Y. Liu, L. M. Si, M. Wei, P. Yan, P. Yang, H. Lu, C. Zheng, Y. Yuan, J. Mou, X. Lv, and H. Sun, "Some recent developments of microstrip antenna, " International Journal of Antenna Propagation, vol. 20, p. 428284, 2012.

[2] Federal Communications Commission (FCC), Revision of Part 15 the Commission's Rules Regarding Ultra-Wideband Transmission Systems First Rep. and Order, ET Docket 98-153, FCC 02-48, Adopted: Feb. 2002; Released, Apr. 2002.

[3] A. I. Najam, Y. Duroc, and S. Tedjni, "UWB-MIMO Antenna with Novel Stub Structure," Progress In Electromagnetics Research C, vol. 19, pp. 245-257, 2011.

[4] G. Lin, C. Sung, J. Chen, L. Chen and M. Houng, "Isolation Improvement in UWB MIMO Antenna System Using Carbon Black Film," IEEE Antennas and Wireless Propagation Letters, vol. 16, pp. 222-225, 2017.

[5] R. Gurjar, D. K. Upadhyay, B. K. Kanaujia, and A. Kumar, "A compact modified Sierpinski carpet fractal UWB MIMO antenna with square-shaped funnel-like ground stub, " International Journal of Electronics and Communications (AEU), vol. 117, pp. 1$10,2020$.

[6] D. Sarkar and K. V. Srivastava, "A compact four- element MIMO diversity antenna with enhanced band-width," IEEE Antennas and Wireless Propagation Letters, vol. 16, pp. 2469-2472, 2017.

[7] J. Tang et al., "A Metasurface Superstrate for Mutual Coupling Reduction of Large Antenna Arrays," IEEE Access, vol. 8, pp. 126859-126867, 2020. 
[8] M. Alibakhshikenari, M. Khalily, B. S. Virdee, C. H. See, R. A. Abd-Alhameed, and E. Limiti, "Mutual Coupling Suppression between Two Closely Placed Microstrip Patches Using EM-Bandgap Metamaterial Fractal Loading," IEEE Access, vol. 7, pp. 23606-23614, 2019.

[9] R. N.Tiwari, P. Singh, B. K. Kanaujia, and K. Srivastava, "Neutralization technique based two and four port high isolation MIMO antennas for UWB communication," International Journal of Electronics and Communications (AEU), vol. 110, p.152828, 2019.

[10] S. Zhang and G. F. Pedersen, "Mutual Coupling Reduction for UWB MIMO Antennas with a Wideband Neutralization Line," IEEE Antennas and Wireless Propagation Letters, vol. 15, pp. 166-169, 2016.

[11] M. Koohestani, A. A. Moreira, and A. K. Skrivervik, "A Novel Compact CPW-Fed Polarization Diversity Ultrawideband Antenna," IEEE Antennas and Wireless Propagation Letters, vol. 13, pp. 563-566, 2014.

[12] L. Liu and T. I. Yuk, "Compact MIMO Antenna for Portable Devices in UWB Applications," IEEE Transactions on Antennas and Propagation, vol. 61, no. 8, pp. 4257-4264, 2013.

[13] J. Ren, W. Hu, Y. Yin, and R. Fan, "Compact Printed MIMO Antenna for UWB Applications," IEEE Antennas and Wireless Propagation Letters, vol. 13, pp. 1517-1520, 2014.

[14] M. Sharma, Y. K. Awasthi, and H. Singh, "Design of CPW-Fed High Rejection Triple Band-Notch UWB Antenna on Silicon Substrate with Diverse Wireless Applications," Progress In Electromagnetics Research C, vol. 74, pp. 19-30, 2017.

[15] S. Mandal, A. Karmakar, H. Singh, S.K. Mandal, R. Mahapatra, and A.K. Mal, "A miniaturized CPW-fed on-chip UWB monopole antenna with band-notch characteristics, " International Journal of Microwave and Wireless Technologies, vol. 25, pp. $1-8,2019$.

[16] X. Zhang, T. L. Zhang, Y. Y. Xia, Z. H. Yan, and X. M. Wang, "Planar Monopole Antenna with Band-Notch Characterization for UWB Applications," Progress In Electromagnetics Research Letters, vol. 6, pp. 149-156, 2009.

[17] J. Banerjee, A. Karmakar, R. Ghatak, and D. R. Poddar, "Compact CPW-fed UWB MIMO antenna with a novel modified Minkowski fractal defected ground structure (DGS) for high isolation and triple band-notch characteristic, " Journal of Electromagnetic Waves and Applications, vol. 31, no. 15, pp. 1550-1565, 2017.

[18] D. Sarkar, K. V. Srivastava, and K. Saurav, "A Compact Microstrip- Fed Triple Band-Notched UWB Monopole Antenna," IEEE Antennas and Wireless Propagation Letters, vol. 13, pp. 396-399, 2014.

[19] Z. Li, C. Yin, and X. Zhu, "Compact UWB MIMO Vivaldi Antenna With Dual Band-Notched Characteristics," IEEE Access, vol. 7, pp. 38696-38701, 2019.

[20] R. Sanmugasundaram, N. Somasundaram, and R. Rengasamy, "Ultrawideband Notch Antenna with EBG Structures for WiMAX and Satellite Application," Progress In Electromagnetics Research Letters, vol. 91, pp. 25-32, 2020.

[21] X. L. Liu, Y. Z. Yin, P. A. Liu, J. H. Wang, and B. Xu, "A CPW-Fed Dual Band-Notched UWB Antenna with a Pair of Bended Dual-L-Shape Parasitic Branches," Progress In Electromagnetics Research, vol. 136, pp. 623-634, 2013.

[22] P. Palanisamy and M. Subramani, "Design and Experimental Analysis of Miniaturized Octa-Port UWB/SWB-MIMO Antenna With Triple-Band Rejection Characteristics, " IETE Journal of Research, vol.12, pp. 231-238, 2020.

[23] D. T. Nguyen, D. H. Lee, and H. C. Park, "Very Compact Printed Triple Band-Notched UWB Antenna With QuarterWavelength Slots," IEEE Antennas and Wireless Propagation Letters, vol. 11, pp. 411-414, 2012.

[24] S. Luo, Y. Chen, D. Wang, Y. Lia, and Y. Li, "A monopole UWB antenna with sextuple band-notched based on SRRs and Ushaped parasitic strips, " International Journal of Electronics and Communications (AEU), vol. 35, pp. 12-19, 2020.

[25] Z. Tang, J. Zhan, X. Wu, Z. Xi, L. Chen, and S. Hu, "Design of a compact UWB-MIMO antenna with high isolation and dual band-notched characteristics, "Journal of Electromagnetic Waves and Applications, vol. 25. pp. 69-76, 2020.

[26] S. M. Khan, A. Iftikhar, S. M. Asif, A. D. Capobianco, and B. D. Braaten, "A compact four elements UWB MIMO antenna with on-demand WLAN rejection, " Microwave Optical Technology Letters, vol. 58, no. 2, pp. 270-276, 2016.

[27] D.K. Raheja, B.K. Kanaujia, and S. Kumar, "Compact four-port MIMO antenna on slotted-edge substrate with dual-band rejection characteristics, " International Journal of RF and Microwave Computer Aided Engineering, vol. 29, no. 7, pp. 1-10, 2019.

[28] V. S. D. Rekha, P. Pardhasaradhi, B. T. P. Madhav, and Y. U. Devi, "Dual Band Notched Orthogonal 4-Element MIMO Antenna with Isolation for UWB Applications," IEEE Access, vol. 8, pp. 145871-145880, 2020.

[29] A. Iqbal, O. A. Saraereh, A. W. Ahmad, and S. Bashir, "Mutual Coupling Reduction Using F-Shaped Stubs in UWB-MIMO Antenna," IEEE Access, vol. 6, pp. 2755-2759, 2018. 
Figures

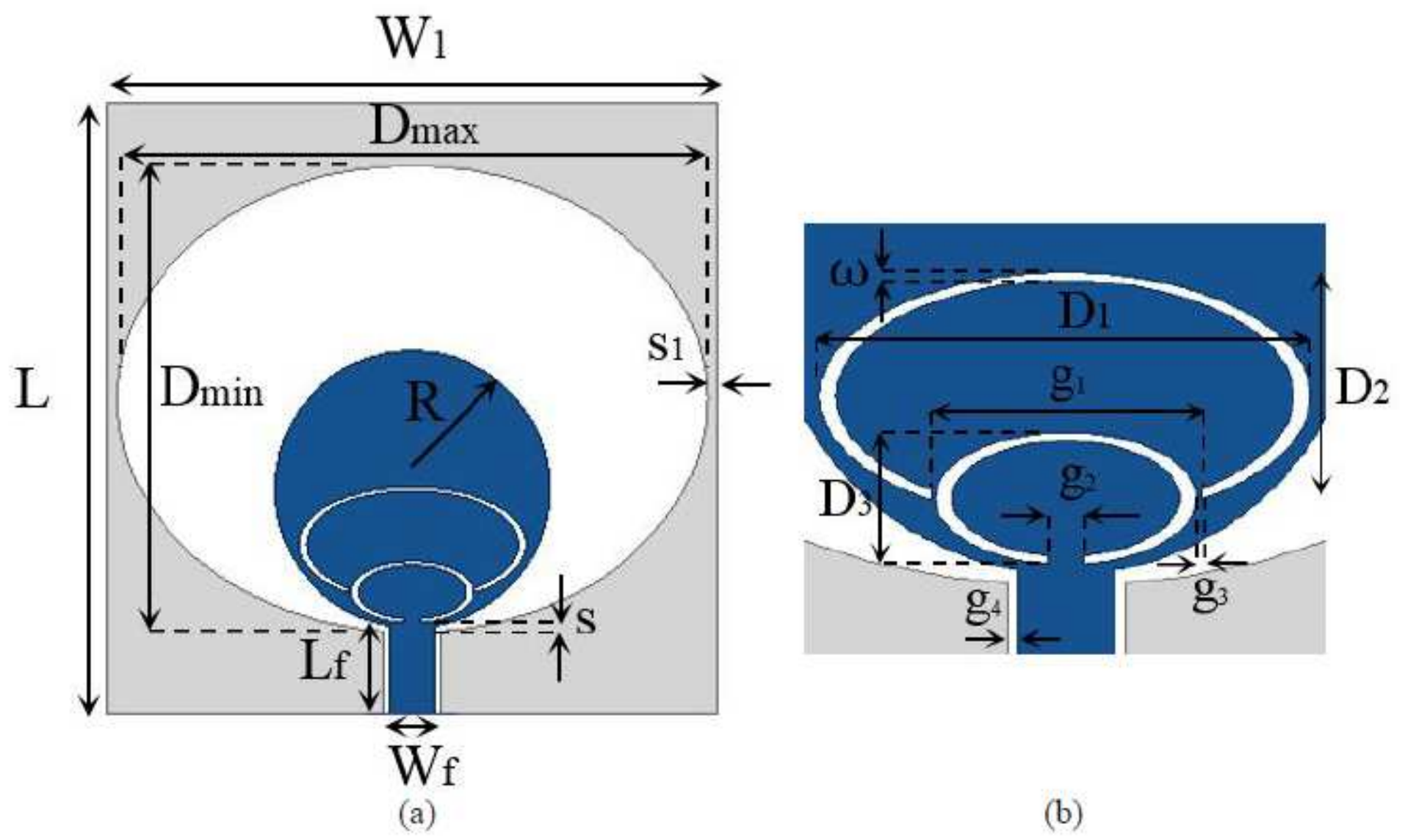

Figure 1

The SISO SWB dual band-notched antenna. (a) Antenna configuration, (b) ESCSRRs. 


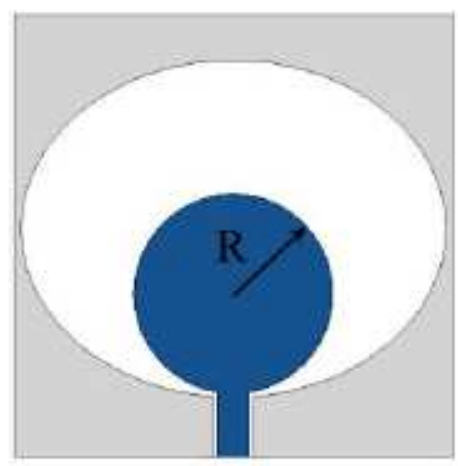

(a)

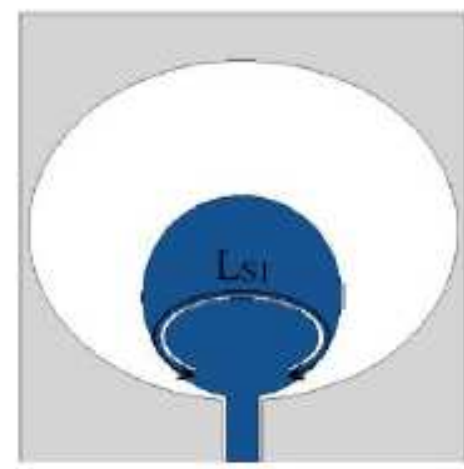

(b)

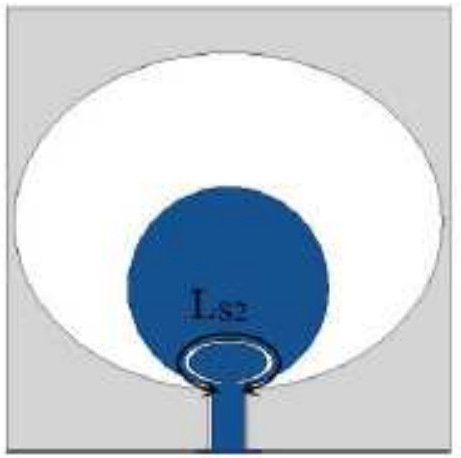

(c)

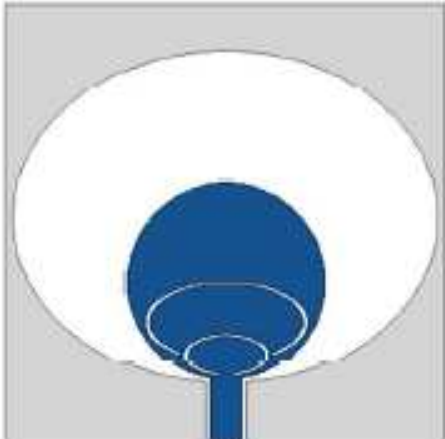

(d)

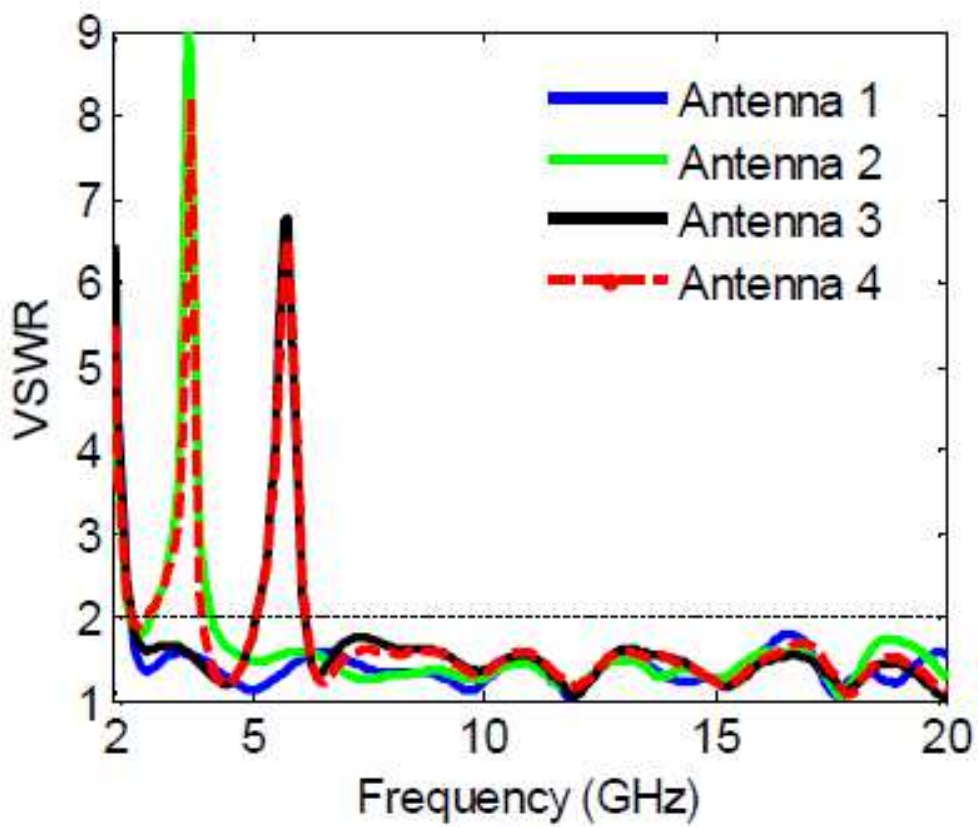

(e)

\section{Figure 2}

The design stages of the SISO SWB dual band-notched antenna, (a) Antenna 1, (b) Antenna 2, (c) Antenna 3, (d) Antenna 4 and (e) Simulated VSWR curves for each step.

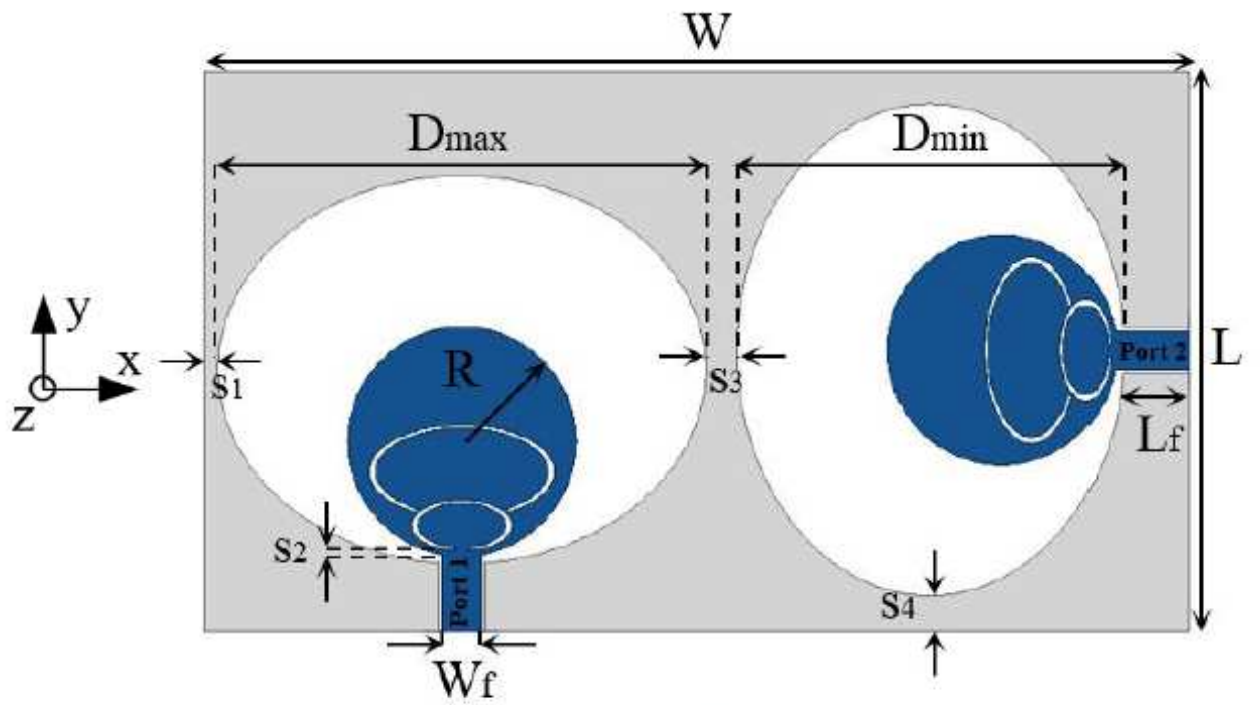

(a)

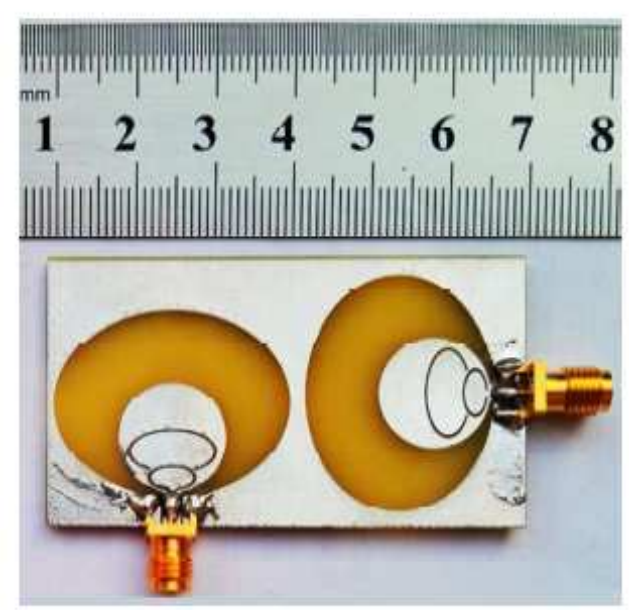

(b) 
Figure 3

The SWB dual band-notched MIMO antenna, (a) Antenna configuration, (b) fabricated prototype.

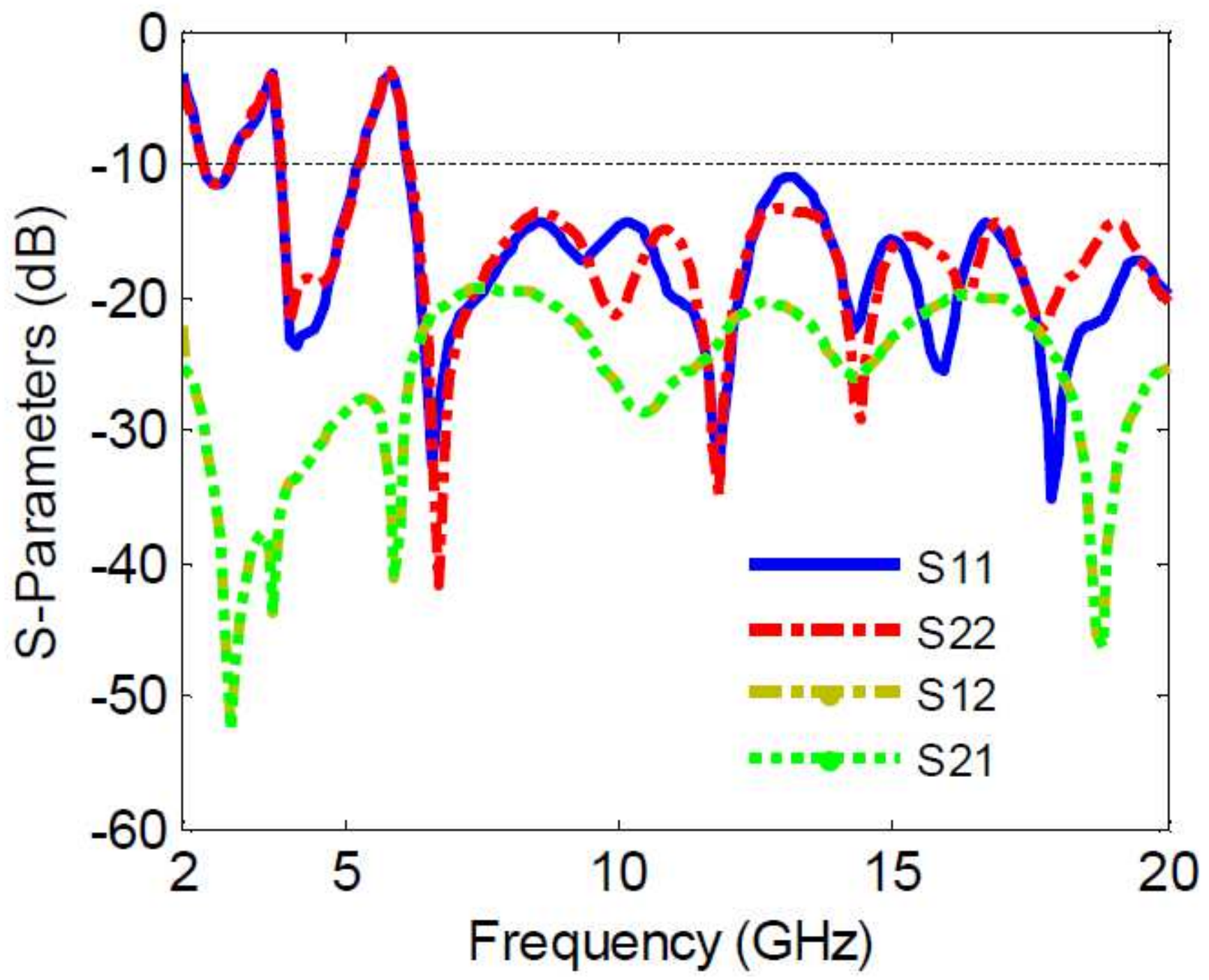

Figure 4

Simulated S-parameters (S11, S12, S21 and S22) of the designed SWB dual band-notched MIMO antenna. 


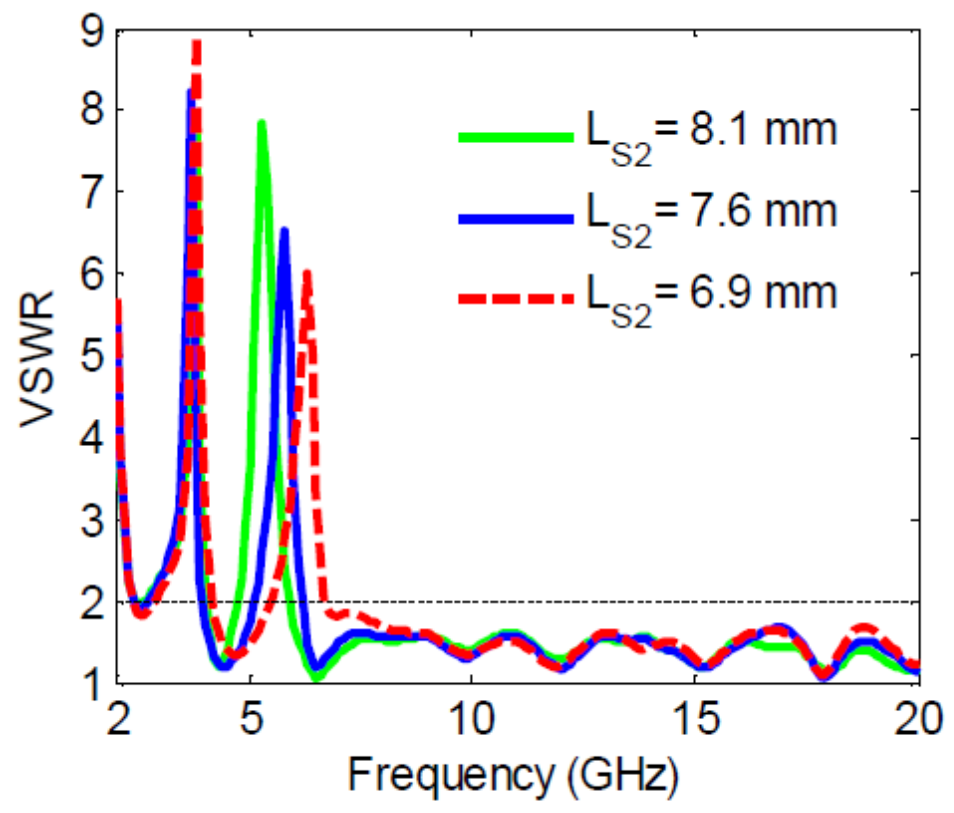

(a)

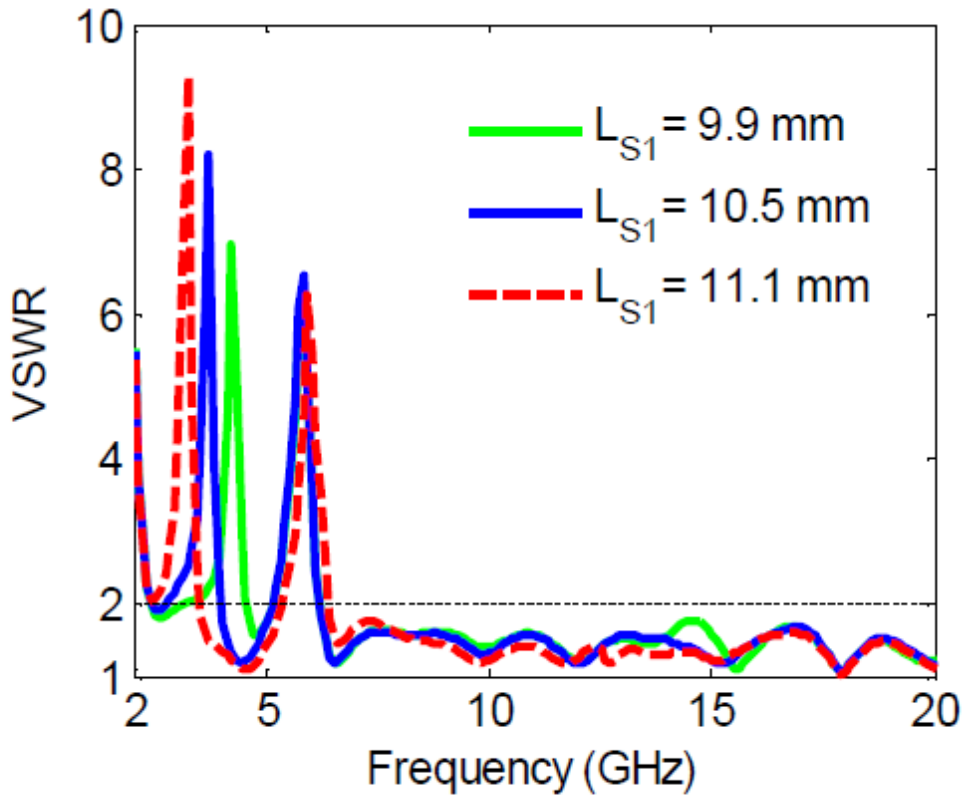

(b)

Figure 5

Parametric study of the total length variation of ESCSRRs, (a) LS2, (b) LS1. 


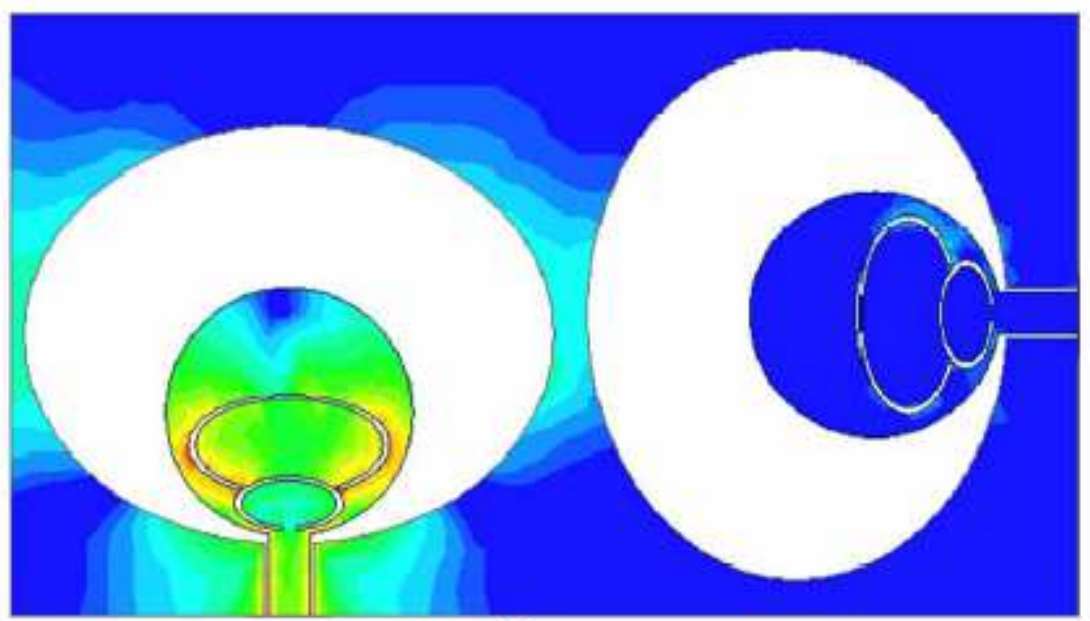

(a)

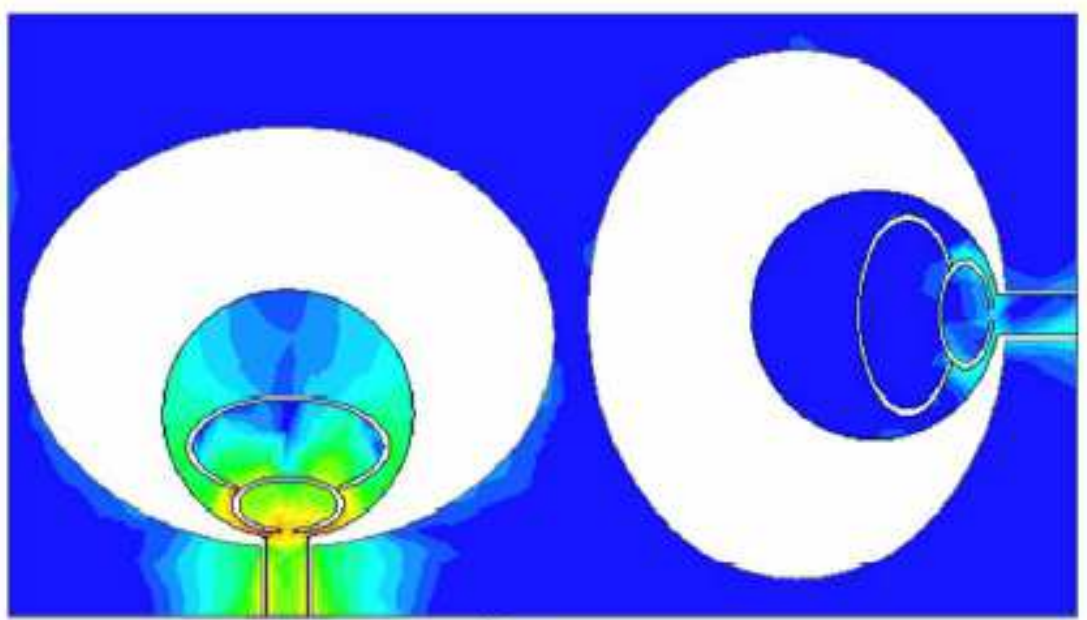

(b)
Jsurf [A_per_m]

1. $0871 e+003$

7. $0592 e+002$

4. $5841 e+002$

2. $9768 e+002$

1. $9331 e+002$

1. $2553 e+002$

8. $1518 e+001$

5. $2936 e+001$

3. $4376 e+001$

2. $2323 e+001$

1. $4496 e+001$

9. $4135 e+000$

6. $1130 \mathrm{e}+000$

3. $9697 e+000$

2. $5778 e+000$

1. $6740 e+000$

1. $0871 \mathrm{e}+000$

\section{Figure 6}

Surface current distribution of the band-notched antenna (a) $3.6 \mathrm{GHz}$, (b) $5.8 \mathrm{GHz}$.

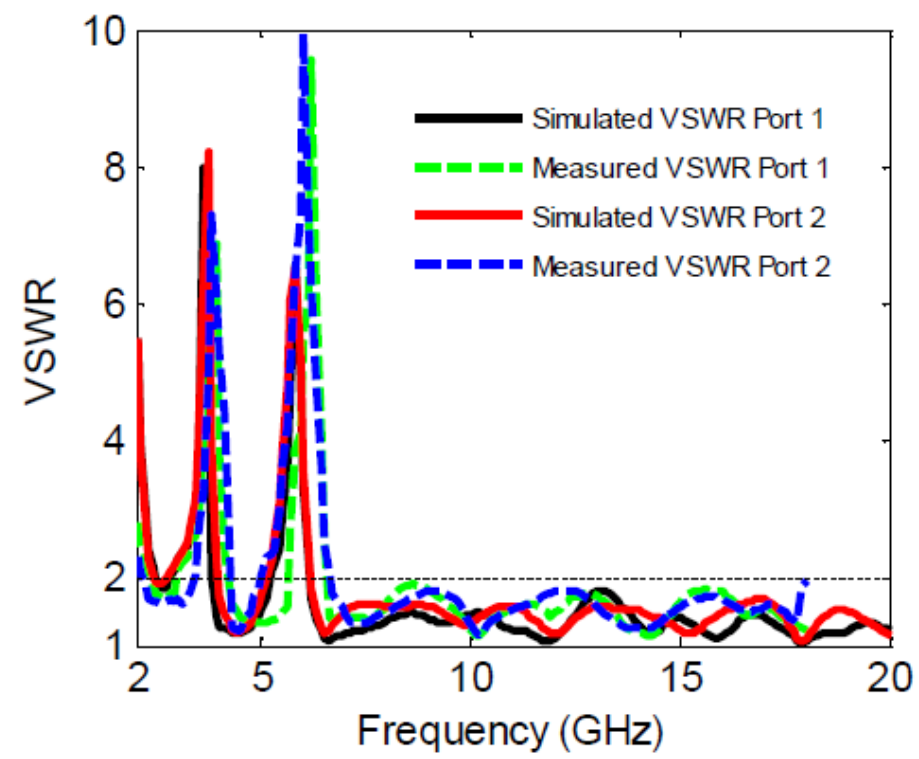

(a)

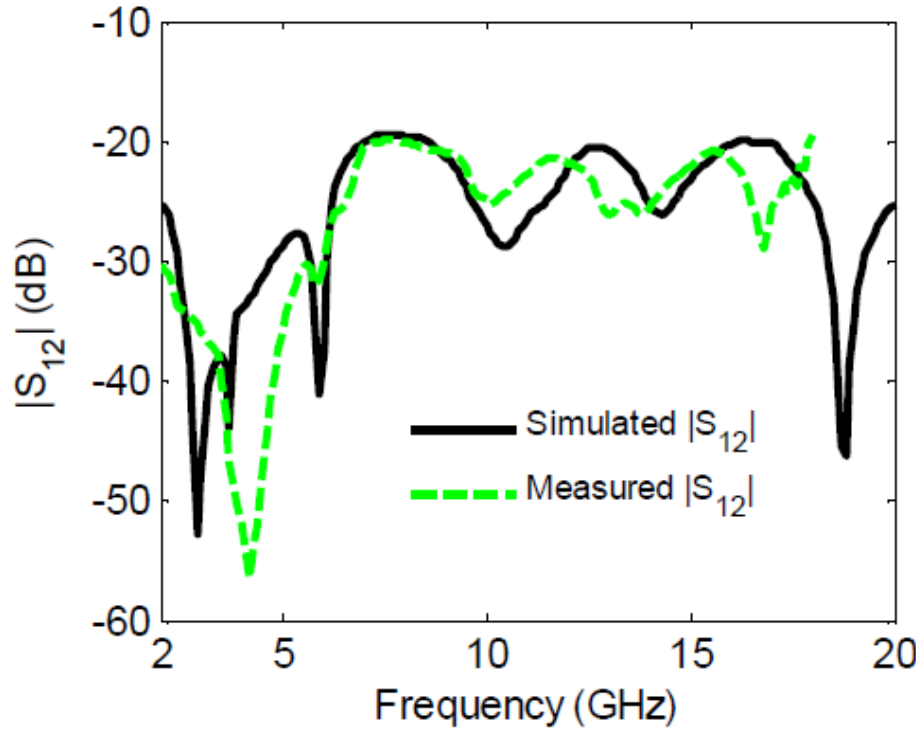

(b) 
Figure 7

Simulated and measured (a) VSWR parameters for each port, (b) amplitude of mutual coupling (S12).
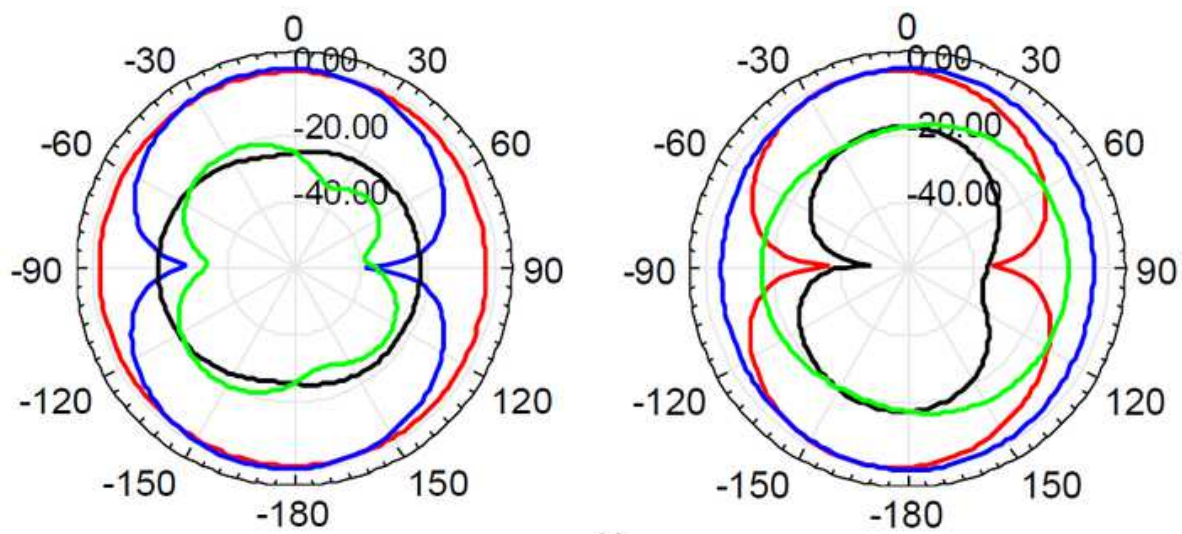

(a)
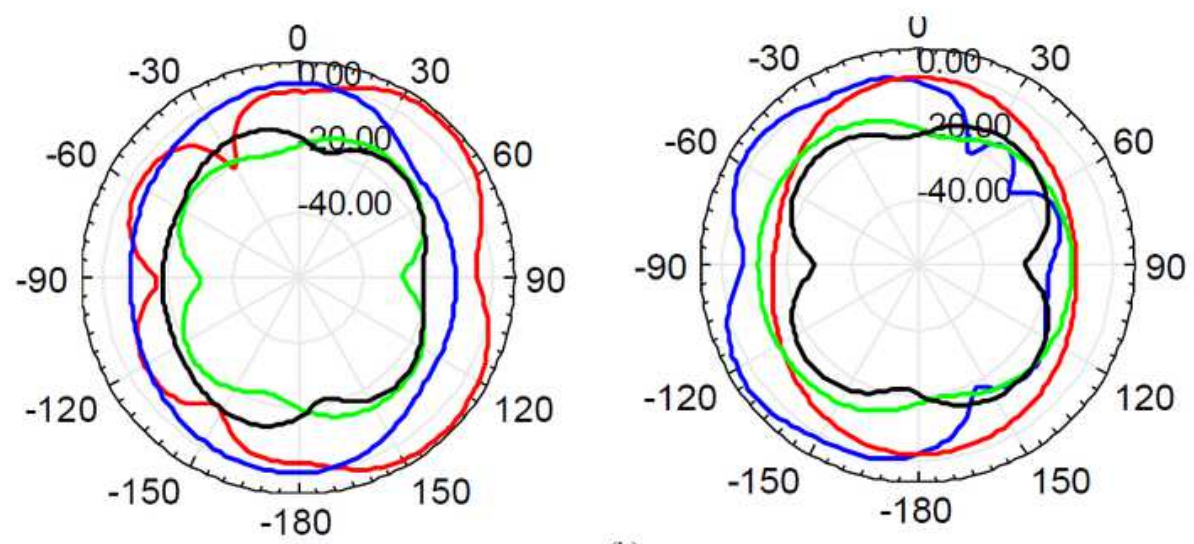

(b)
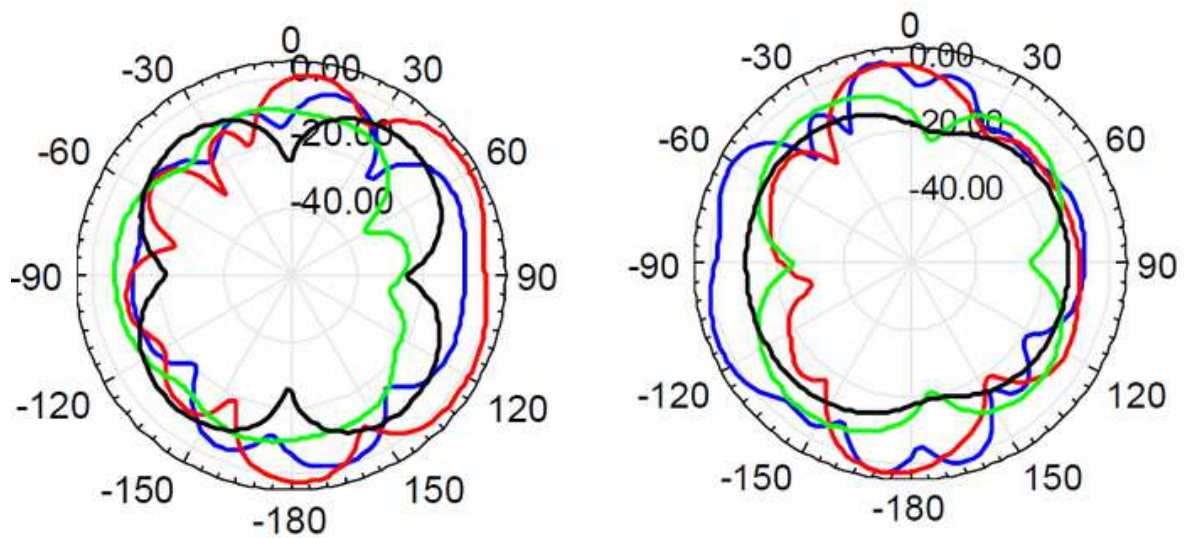

(c)

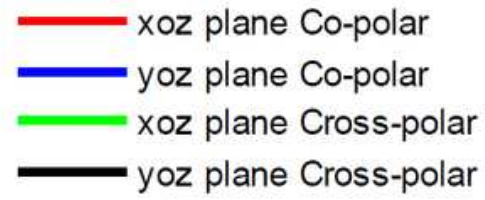

Figure 8

Simulated radiation patterns in $\operatorname{xoz}\left(\varphi=0^{\circ}\right)$ and yoz $\left(\varphi=90^{\circ}\right)$ planes at (a) $3 \mathrm{GHz}$, (b) $10 \mathrm{GHz}$, (c) $17 \mathrm{GHz}$, when port 1 is excited and port 2 terminated by a matched load (right), port 2 is excited and port 1 
terminated by a matched load (left).

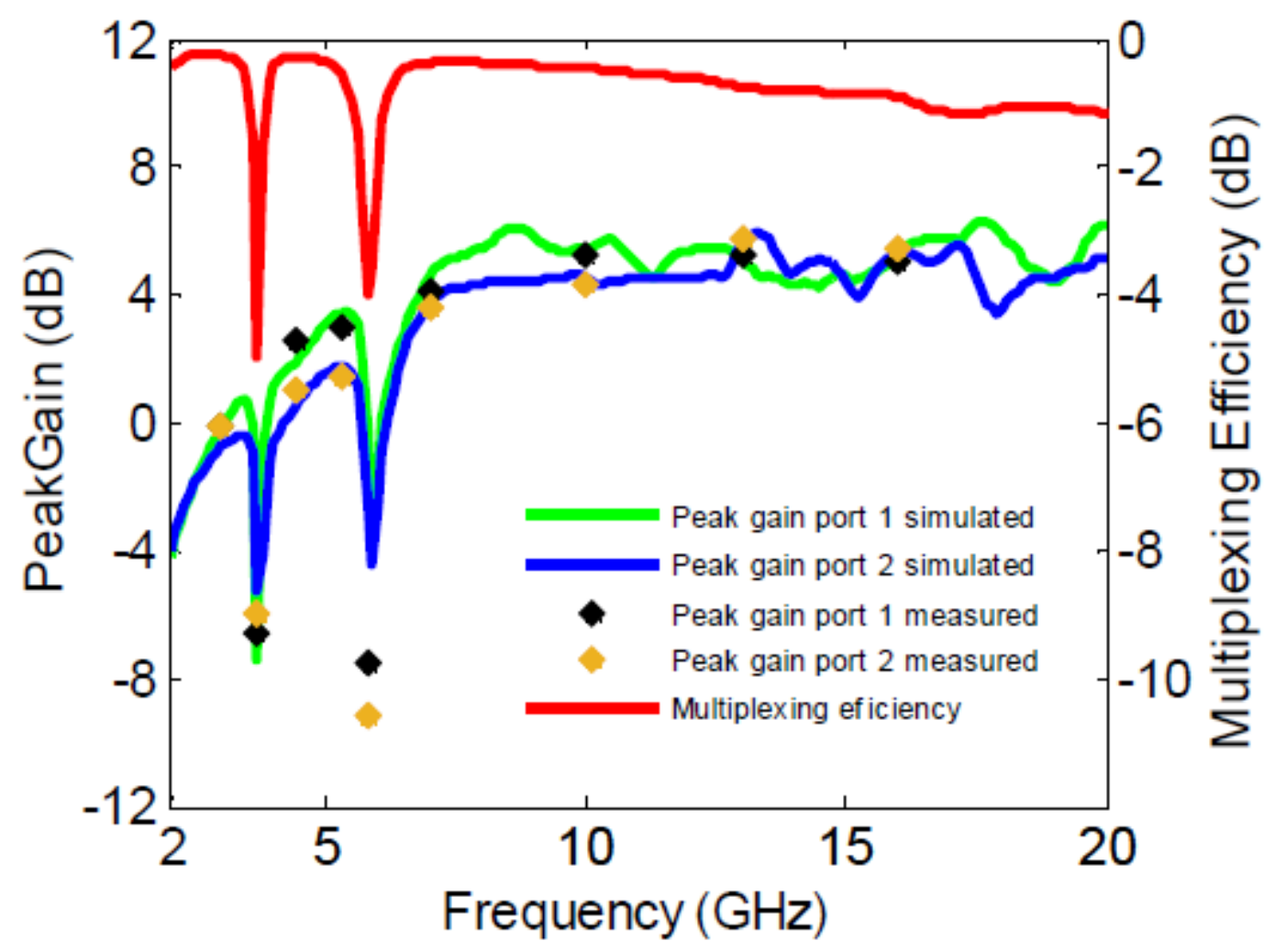

Figure 9

Simulated peak gain and multiplexing efficiency of the designed SWB MIMO antenna.

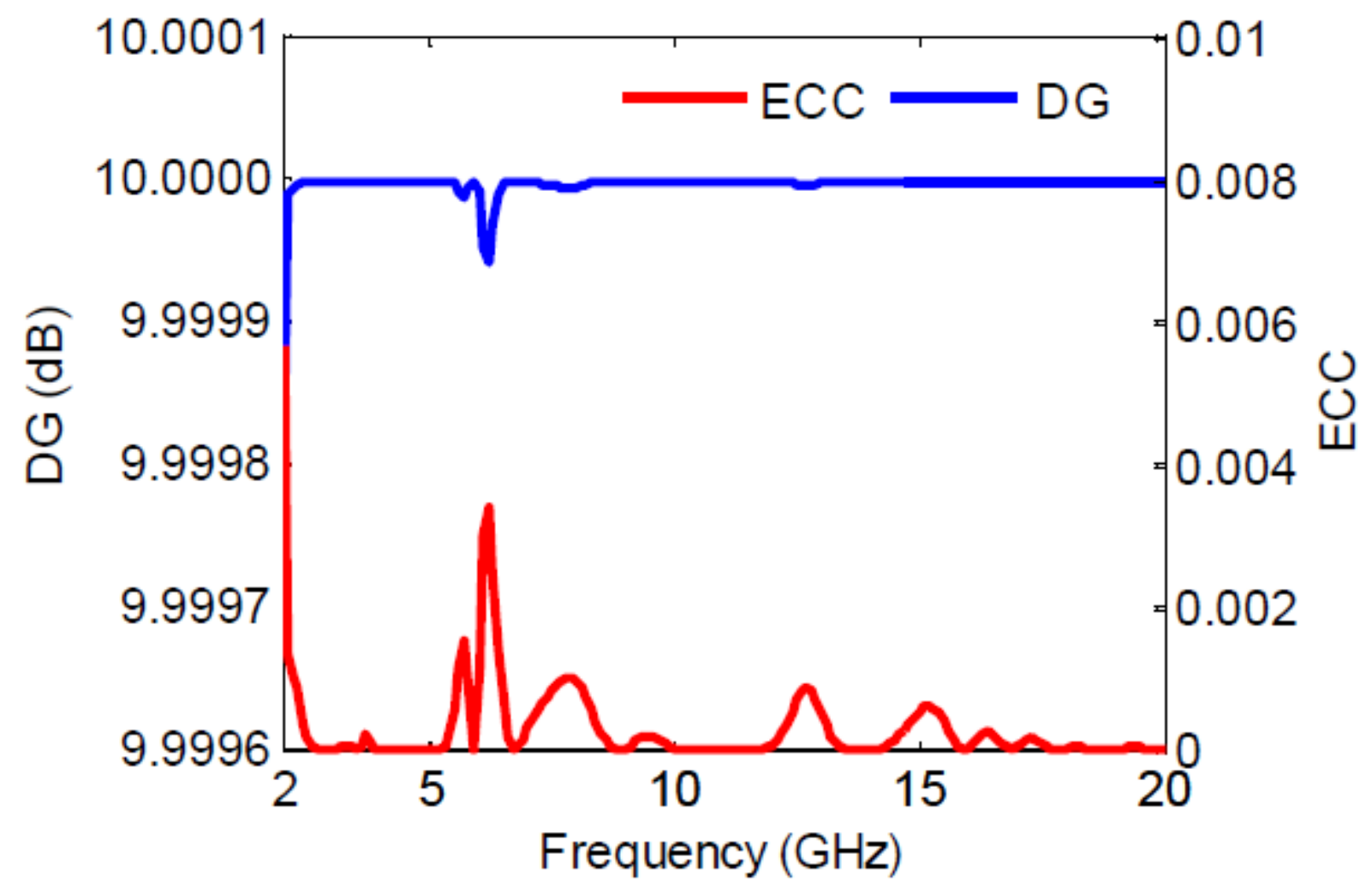


Figure 10

Simulated DG and ECC of the designed SWB dual band-notched MIMO antenna. 